\title{
Benefits of inclined pile foundations in earthquake resistant design of bridges*
}

\author{
Francisco González ${ }^{\dagger}, \mathrm{a}$, Sandro Carbonari ${ }^{\mathrm{b}}$, Luis A. Padrón ${ }^{\mathrm{a}}$, Michele Moricic ${ }^{\mathrm{c}}$, Juan \\ J. Aznárez ${ }^{\mathrm{a}}$, Francesca Dezi ${ }^{\mathrm{d}}$, Orlando $\mathrm{Maeso}^{\mathrm{a}}$, and Graziano Leonic \\ ${ }^{\mathrm{a}}$ SIANI, Universidad de Las Palmas de Gran Canaria, Spain \\ ${ }^{\mathrm{b}}$ DICEA, Università Politecnica delle Marche, Ancona, Italy \\ ${ }^{\mathrm{c}} S A A D$, University of Camerino, Ascoli Piceno, Italy \\ ${ }^{\mathrm{d}}$ DESD, University of San Marino, Republic of San Marino
}

\begin{abstract}
This paper studies the effects of the use of inclined pile foundations on the seismic response of bridges, and shows that this type of foundation is able to promote significant reductions in the ductility demand of reinforced concrete piers. To this end, a set of nine multi-span roadway viaducts with different pier heights and span lengths is defined. Each configuration is designed and dimensioned in detail following a displacement-based approach, considering both linear and non-linear expected behaviours and assuming different target ductilities for piers. The systems are assumed to be founded on a specific soil profile, and suitable pile foundation layouts and dimensions are determined for each case, with four different pile rake angles (including the vertical case) in each configuration. Soil-structure interaction phenomena are incorporated through the corresponding frequency-dependent impedance functions and kinematic interaction factors. The transverse response of the viaducts, subject to a set of seven suitable scaled real accelerograms, is computed and analysed making use of a substructuring approach and nonlinear time-domain analysis in which a lumped parameter model is adopted to represent the foundation response. Results, presented not only in terms of ductility demand but also of energy dissipated in the structural system by damping or by yielding, suggest that inclined piles are clearly beneficial to the seismic response of bridges, contributing to significant reductions in ductility demand due to the particular kinematic seismic response of this type of foundations and associated reductions in the input seismic energy to the system.
\end{abstract}

Keywords: ductility demand; inclined piles; soil-structure interaction; bridge seismic response; pile foundation; reinforced concrete pier; lumped parameter model; displacement-based seismic design approach.

${ }^{*}$ This is the peer reviewed version of the following article: F. González, S. Carbonari, L. A. Padrón, M. Morici, J. J. Aznárez, F. Dezi, O. Maeso, G. Leoni, Benefits of inclined pile foundations in earthquake resistant design of bridges, Engineering Structures, 203:109873, 2020, which has been published in final form at https://doi.org/10.1016/j.engstruct.2019.109873. This article may be used for non-commercial purposes in accordance with Elsevier Terms and Conditions for Accepted Manuscripts.

${ }_{\dagger}$ Corresponding author: Francisco González, Instituto Universitario de Sistemas Inteligentes y Aplicaciones Numéricas en Ingeniería, Universidad de Las Palmas de Gran Canaria, Edificio Central del Parque Científico y Tecnológico del Campus Universitario de Tafira, 35017 Las Palmas de Gran Canaria, Spain.

Email: francisco.gonzalez@ulpgc.es 


\section{Introduction}

The earthquake resistance of civil structures is based on the concept of energy dissipation, since it would be economically unfeasible to guarantee an elastic response of structures for severe actions. In the case of bridges, namely for strategic structures characterised by high costs of construction, the task of reducing the seismic damage, and hence repair costs after an earthquake, is of paramount important to assure a good resilience to the society.

Besides the well-known approaches based on seismic passive protection systems, which foresee the use of isolators (such as elastomeric bearings, lead rubber bearings, single or double concave friction pendulums) with or without supplementary dissipative devices (such as viscous dampers) $[1,2,3,4,5]$, the research is also focusing on innovative solutions that take advantage of the inelastic dissipative capabilities of piers, as demonstrated by recent numerical and experimental investigations presented in $[6,7,8,9]$.

With reference to bridges developing ductile inelastic mechanisms in the piers under earthquake loading, the role of Soil-Structure Interaction (SSI) in the inelastic behaviour has been investigated in the literature mainly focusing on the effects induced by surface or vertical pile foundations.

SSI effects on inelastic bridge response were studied by Ciampoli and Pinto in 1995 [10] by considering a spread footing foundation. They found that, for the analysed set of foundation layouts, SSI effects were not significant, as the inelastic demand remained unaffected. One year later, Elnashai and McClure [11] studied the case of bridge piers on pile foundations, finding that SSI plays a significant role in the response of the system and thus should be included in the seismic assessment, being ductility demand significantly affected by the inclusion of piles. Later, Mylonakis and Gazetas [12] found, through parametric analyses, that SSI in inelastic bridge piers supported on deformable soil may cause significant increases in the ductility demand of the piers, depending on the characteristics of the motion and the structure. The work of Jeremic et al. [13], studying the influence of SSI in the I-880 viaduct, supported this idea and showed that detrimental effects of SSI can be observed depending on the soil properties and on the characteristics of the ground motion [12, 13]. Looking more deeply into this issue, the role of SSI on the collapse of the Hanshin Expressway was analysed by Mylonakis et al. [14]. The bridge consisted of single circular concrete piers monolithically connected to a concrete deck with 18 spans in total, founded on groups of 17 piles in layers of loose to dense sands and moderate to stiff clays. They found that the compliance of the foundation increased the participation of the fundamental mode of the structure, inducing a stronger response. It was shown that the increase in inelastic seismic demand in the piers had exceeded $100 \%$ in comparison with piers fixed at the base.

The analysis of previous observations concerning the seismic damage in bridge piers reveals that the characteristics of the induced foundation input motions may play an important role on the bridge response. In this framework, peculiarities of the filtering effects exerted by inclined piles, mainly consisting in an overall reduction of the input motion to the system, are worth of investigation. One of the most important mechanisms, which characterise the kinematic response of inclined pile foundations, is constituted by foundation rotations which are responsible of anti-phase displacements and accelerations of the superstructures, with respect to those induced by the horizontal components of the seismic action. Beneficial effects were found in idealised linear systems, e.g. [15, 16, 17], but as far as the authors know, the effects on the ductility demand of bridge piers have not been studied yet.

This paper focuses on the potential benefits of the use of inclined piles for the piers foundations of multi-span bridges in earthquake-prone areas. To this end, a set of bridges characterized by different pier heights and span lengths are defined together with their corresponding pile foundations. The structures are designed following a displacement-based approach [18], and both linear and non-linear behaviours are taken into account assuming different target ductility demands. For each foundation, four different pile rake angles are considered (including the vertical case), and the response of all 


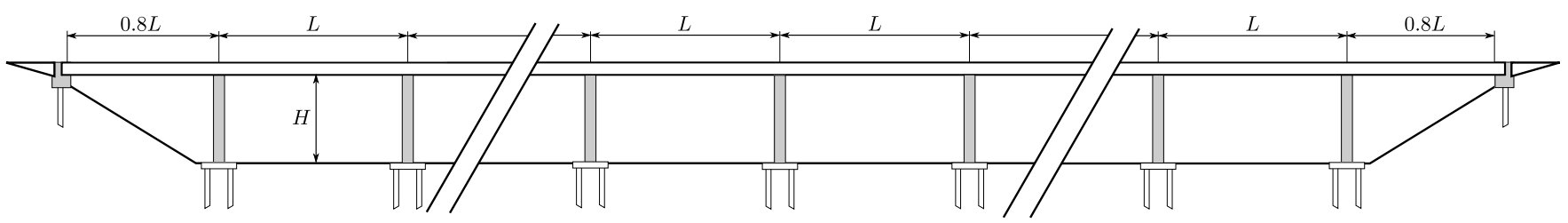

(a)

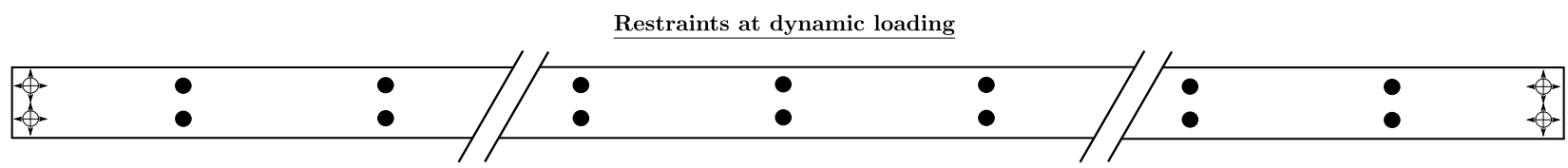

(b)

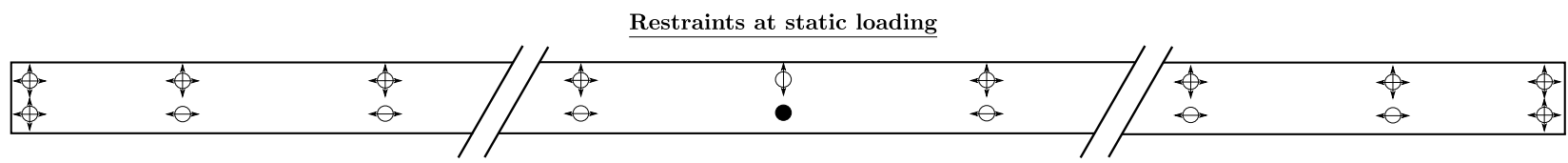

(c)

\$-Multidirectional support $\quad \ominus$ - Unidirectional support $\quad$ - Fixed support

Figure 1: (a) Viaduct longitudinal view and restraint conditions of the deck under (b) dynamic and (c) static loading.

resulting configurations, each subject to a set of seven scaled real accelerograms, is computed and analysed making use of a substructuring approach [19] and non-linear time-domain analysis. The non-linear behaviour of the bridge piers is modelled using both Takeda's [20] and a bilinear model. On the other hand, the frequency-dependent behaviour of the pile foundations is incorporated in the analysis by Lumped Parameter Models (LPM) calibrated to reproduce impedance functions previously computed for each specific case.

Results are presented in terms of ductility demand and energy dissipated by damping or by yielding. The results suggest that inclined piles are clearly beneficial to the seismic response of bridges, contributing to significantly reduce the ductility demand of piers due to the particular kinematic seismic response of this type of foundations and the associated reductions in the input seismic energy to the system.

\section{Problem definition}

The study will focus on the transverse seismic response of multi-span roadway viaducts characterised by identical pier heights and constant span lengths, with the exception of the edge ones, which are reduced to the $80 \%$ to optimise distribution of positive bending moments due to moving loads (Figure 1a). At dynamic conditions, the deck is rigidly connected to all piers both in the longitudinal and transverse directions (Figure 1b), through the use of shock transmitters that allow free elongations of the deck due to thermal actions at static conditions (Figure 1c). Finally, the deck is disconnected at the abutments in the longitudinal and transverse directions through the use of multi sliding bearings, to avoid the development of dual load path mechanisms resisting the seismic actions.

By assuming a synchronous seismic motion at all supports, above assumptions assure that the deck transverse deflections due to the out-of-phase seismic transverse response of piers are negligible [21] and the seismic response of the bridge can be studied through a single degree of freedom system representative of a single pier with its tributary deck mass. Thus, bridge decks are designed for vertical actions, including moving loads, while piers are designed to withstand the seismic actions. 


\begin{tabular}{c|cccc} 
& \multicolumn{2}{|c}{ Depth } & & \\
& $\begin{array}{c}\text { from } \\
{[\mathbf{m}]}\end{array}$ & $\begin{array}{c}\text { to } \\
{[\mathbf{m}]}\end{array}$ & $\begin{array}{c}c_{s} \\
{\left[\mathbf{m s}^{-\mathbf{1}}\right]}\end{array}$ & $\begin{array}{c}\rho_{s} \\
{\left[\mathbf{t m}^{-3}\right]}\end{array}$ \\
\hline Lithotype 1: & 0.0 & 15.0 & 120.0 & 1.8 \\
normally consolidated clay & 15.0 & 30.0 & 180.0 & 1.8 \\
\hline Lithotype 2: & 30.0 & 40.0 & 600.0 & 2.0 \\
over consolidated clay & 40.0 & $\infty$ & 800.0 & 2.0
\end{tabular}

Table 1: Soil profile and lithotypes.

Bridges characterised by different span lengths $L(25,50$ and $75 \mathrm{~m})$ and piers heights $H(10,15$ and $30 \mathrm{~m}$ ) are assumed, covering a sufficiently wide scenario of aspect ratio $L / H$, and the design is performed taking advantage of the above assumptions on the deck restraints. In addition, bridges with both a ductile and non-ductile behaviour are designed imposing the displacement ductility demand of piers through a displacement-based design approach [18]. Finally, pile foundations are designed following standard guidelines, taking into account design action effects at the base of each pier, evaluated according to hierarchy principles [22], and the site class.

\subsection{Soil properties and seismic actions}

A layered type D soil profile, representative of loose-to-medium cohesionless soil or predominantly soft-to-firm cohesive soil, according to EC8-1 [23], is considered in this study. The soil is assumed to be constituted by two fundamental lithotypes, normally and over consolidated (geological bedrock) clays characterized by the properties reported in Table 1, with an ascending soil shear wave's velocity $c_{s}$ from $120.0 \mathrm{~m} / \mathrm{s}$ to $800.0 \mathrm{~m} / \mathrm{s}$. A constant Poisson's ratio $\nu_{s}=0.4$ is assumed for both lithotypes.

The seismic action is constituted by a set of seven scaled real accelerograms, chosen from the Selected Input Motions for displacement-Based Assessment and Design database, SIMBAD [24]. The records selection is based on the earthquake Magnitude $\left(5.0<\mathrm{M}_{\mathrm{w}}<7.3\right)$, the epicentral distance $(0.0<\Delta<35.0 \mathrm{~km})$ and the mean pseudo-acceleration and displacement response spectra compatibility with the design ones, defined according to the EC8-1 [23], for which a peak ground acceleration of $0.3375 \mathrm{~g}$ is expected on soil $\mathrm{D}$ at the life safety limit state. Compatibility of the mean pseudo-acceleration and displacement response spectra with the code ones is assured within the superstructures minimum and maximum fundamental periods, considering both the elastic and the expected inelastic (i.e. effective) periods, resulting from the displacement-based design procedure, as it will be briefly shown in the sequel. In detail, the mean spectral ordinates result no lower than the $90 \%$ of the relevant ones of the code in the range $0.71<\mathrm{T}<5.00 \mathrm{~s}$, corresponding to the minimum elastic and maximum effective periods of the analysed bridges. Finally, in order to limit bias in the structural response caused by the ground motion selection [25, 26, 27], earthquakes requiring small scale factors (1.00-1.35) are employed. The selected records are detailed in Table 2, and the elastic response spectrum (in terms of pseudo-acceleration and displacement) of each one is compared with the design spectra in Figure 2. In addition, the mean spectra of the selection are shown with a continuous black line, while mean spectra plus and minus the standard deviation are reported with dashed lines to provide a pictorial view of the scattering of spectral ordinates.

\subsection{Decks}

Bridges with span lengths $L$ of 25.0, 50.0 and $75.0 \mathrm{~m}$ are considered and twin girders steel-concrete composite decks with a slab width of $12.0 \mathrm{~m}$ and thickness ranging between 25.0 and $35.0 \mathrm{~cm}$ (Figure 3a) are designed. Since, as already stated, decks are not strongly involved in the seismic response 


\begin{tabular}{|c|c|c|c|c|c|c|c|}
\hline $\begin{array}{c}\text { Earthquake } \\
\text { label }\end{array}$ & $\begin{array}{c}\text { Name } \\
W C-E C\end{array}$ & Station ID & $\begin{array}{c}\text { Date } \\
{[\mathrm{dd} / \mathrm{mm} / \mathrm{yy}]}\end{array}$ & $\begin{array}{c}\Delta \\
{[\mathrm{km}]}\end{array}$ & $\begin{array}{c}\text { Magnitude } \\
{\left[\mathrm{M}_{\mathrm{w}}\right]}\end{array}$ & $\begin{array}{c}P G A \\
{\left[\mathrm{~ms}^{-2}\right]}\end{array}$ & $\begin{array}{l}\text { Scale } \\
\text { factor }\end{array}$ \\
\hline E1 & $\begin{array}{c}\text { Gazli } \\
440-86\end{array}$ & KAR & $17 / 05 / 1976$ & 12.8 & 6.7 & $\begin{array}{l}7.04 \\
x \text {-dir }\end{array}$ & 1.25 \\
\hline $\mathrm{E} 2$ & $\begin{array}{c}\text { Gazli } \\
440-86\end{array}$ & KAR & $17 / 05 / 1976$ & 12.8 & 6.7 & $\begin{array}{l}5.97 \\
y \text {-dir }\end{array}$ & 1.05 \\
\hline E3 & $\begin{array}{c}\text { Imperial Valley } \\
446-89\end{array}$ & EC05 & 15/10/1979 & 27.7 & 6.5 & $\begin{array}{l}5.09 \\
y \text {-dir }\end{array}$ & 1.25 \\
\hline $\mathrm{E} 4$ & $\begin{array}{c}\text { Imperial Valley } \\
447-89\end{array}$ & EC06 & $15 / 10 / 1979$ & 27.4 & 6.5 & $\begin{array}{l}4.03 \\
y \text {-dir }\end{array}$ & 1.00 \\
\hline E5 & $\begin{array}{c}\text { Loma Prieta } \\
456-94\end{array}$ & ST_58065 & 18/10/1989 & 27.6 & 6.9 & $\begin{array}{l}3.18 \\
x \text {-dir }\end{array}$ & 1.35 \\
\hline E6 & $\begin{array}{c}\text { Northridge } \\
461-99\end{array}$ & ST_24279 & 17/01/1994 & 20.3 & 6.7 & $\begin{array}{l}5.78 \\
y \text {-dir }\end{array}$ & 1.00 \\
\hline E7 & $\begin{array}{c}\text { Erzincan } \\
465-78\end{array}$ & ERZ & 13/03/1992 & 8.97 & 6.6 & $\begin{array}{l}4.86 \\
x \text {-dir }\end{array}$ & 1.18 \\
\hline
\end{tabular}

Table 2: Selected records for input motion (WC: Waveform Code, EC: Earthquake Code, $\Delta$ : epicentral distance and PGA: Peak Ground Acceleration.) [24].

\begin{tabular}{ccccccccccccc}
$\begin{array}{c}L \\
{[\mathbf{m}]}\end{array}$ & $\begin{array}{c}M_{\text {hogging }} \\
{[\mathbf{M N m}]}\end{array}$ & $\begin{array}{c}M_{\text {sagging }} \\
{[\mathbf{M N m}]}\end{array}$ & $\begin{array}{c}l_{1} \\
{[\mathbf{m}]}\end{array}$ & $\begin{array}{c}l_{2} \\
{[\mathbf{m}]}\end{array}$ & $\begin{array}{c}l_{3} \\
{[\mathbf{m}]}\end{array}$ & $\begin{array}{c}l_{4} \\
{[\mathbf{m}]}\end{array}$ & $\begin{array}{c}e_{h 1} \\
{[\mathbf{m m}]}\end{array}$ & $\begin{array}{c}e_{h 2} \\
{[\mathbf{m m}]}\end{array}$ & $\begin{array}{c}e_{h 3} \\
{[\mathbf{m m}]}\end{array}$ & $\begin{array}{c}e_{m 1} \\
{[\mathbf{m m}]}\end{array}$ & $\begin{array}{c}e_{m 2} \\
{[\mathbf{m m}]}\end{array}$ & $\begin{array}{c}e_{m 3} \\
{[\mathbf{m m}]}\end{array}$ \\
\hline 25.0 & -10.7 & 7.2 & 6.25 & 1.0 & 0.6 & 0.6 & 50.0 & 50.0 & 15.0 & 20.0 & 30.0 & 10.0 \\
50.0 & -43.0 & 29.0 & 12.5 & 1.9 & 0.8 & 1.0 & 65.0 & 65.0 & 22.0 & 25.0 & 40.0 & 12.0 \\
75.0 & -98.4 & 66.1 & 18.75 & 2.9 & 1.0 & 1.2 & 85.0 & 85.0 & 30.0 & 35.0 & 55.0 & 15.0
\end{tabular}

Table 3: Bending moments due to self weights, and girders plates thicknesses and dimensions (scheme in Figure 3b).

of the bridges, a design for vertical loads is performed considering two types of cross-sections, representative of hogging and sagging deck regions (Figure 3b).

The steel beams height $l_{2}$ is evaluated by assuming $L / l_{2}=26.0$, while thicknesses of webs as well as widths and thicknesses of bottom and top flanges are determined through an elastic analysis of the most stressed cross-sections of the hogging and sagging regions, assuming steel grade S355 for girders and concrete grade C25/30 for the slab. As for the slab, typical longitudinal and transversal reinforcement ratios, corresponding to $1 \%$ and $2 \%$ for the sagging and hogging cross-sections, respectively, are assumed (Figure 3a). For the sake of completeness, Table 3 shows bending moments obtained from the deck analyses subjected to vertical loads (self-weight, moving and permanent loads), and the girders plates dimensions of the hogging and sagging cross-sections relevant to the span lengths of 25,50 and $75 \mathrm{~m}$.

\section{$2.3 \quad$ Piers}

Piers of investigated bridges are designed to withstand the seismic action with both a ductile and nonductile behaviour, in order to evaluate effects of SSI on both linear and non-linear systems. Taking advantage of the decks restraints at dynamic conditions, which foresees all piers of the viaducts subjected to similar inertia forces deriving from the relevant masses of the deck and of the pier itself, a single inner pier of the bridge is considered in the design, neglecting local boundary effects and assuming a fixed base scheme.

Non-ductile piers are designed to remain in the elastic range while ductile piers are designed to 

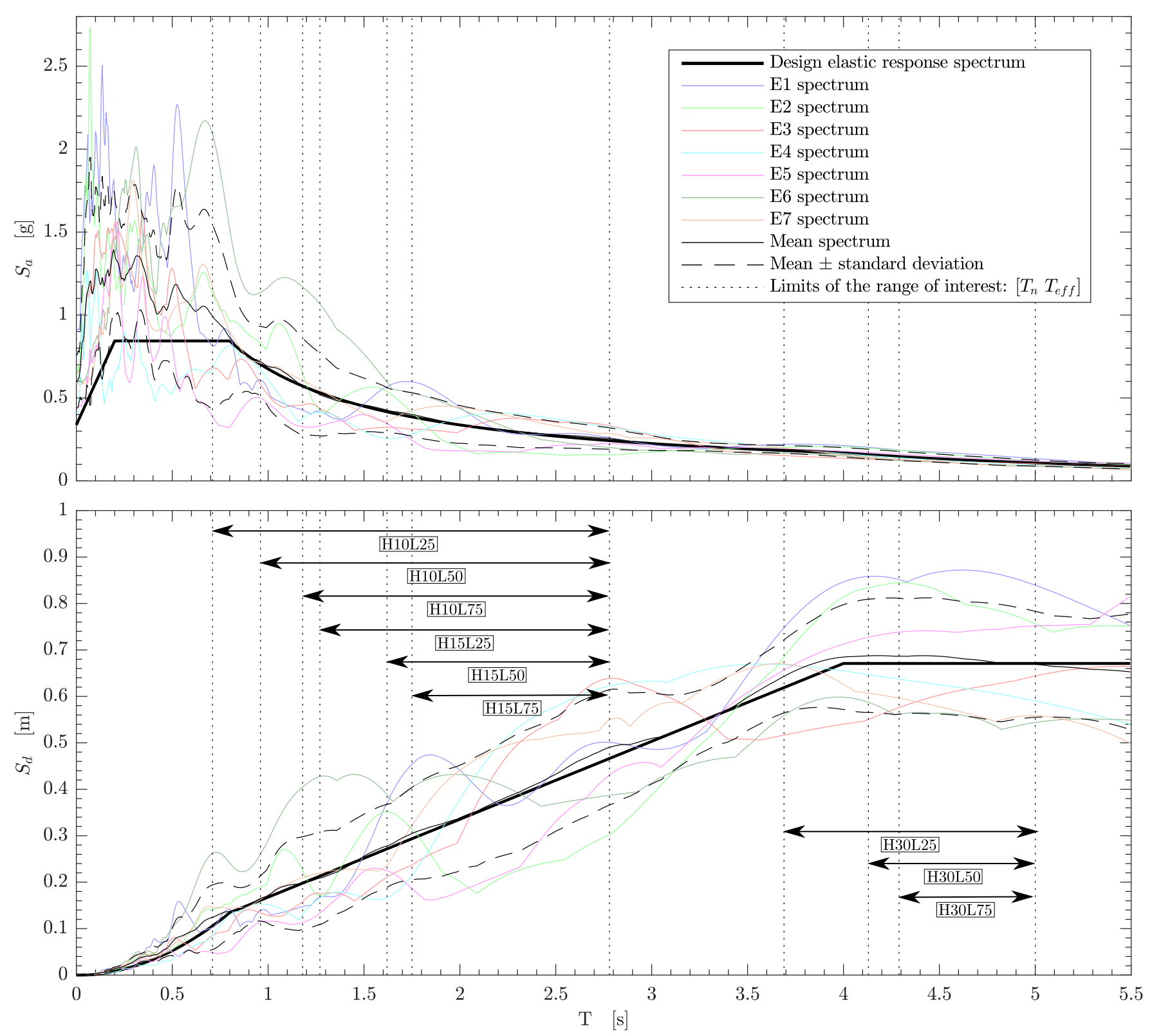

Figure 2: Elastic response spectrum of the selected earthquakes (Table 2), in terms of accelerations (top) and displacements (bottom).

develop dissipative plastic hinges at the base, characterised by a suitable plastic rotation capacity. The displacement-based design approach is adopted to design systems with established ductile performances, in terms of expected piers displacement ductility demand $\mu$ (or expected plastic rotation of hinges at the piers base) [18]. In details, piers with elastic behaviour $(\mu=0.98)$ as well as piers with a displacement expected ductility demand equal to 2.02 and 4.05 are designed, corresponding to piers heights of 10, 15 and $30 \mathrm{~m}$, respectively. The latter are all combined with the three span lengths, generating the nine analysis cases reported in Table 4. Each of the different nine configurations will be identified through the paper using the label defined in the first column of Table 4. As well known, the displacement-based design approach is based on the design of an equivalent single degree of freedom system for which the secant stiffness and equivalent viscous damping properties (depending on the ductility developed by the structural system) are defined, starting from the desired displacement (or ductility) that the system should exhibit when subjected to the design seismic action. The design stems from the definition of the pier cross-section and of the expected displacement demand $\Delta_{d}$ to 


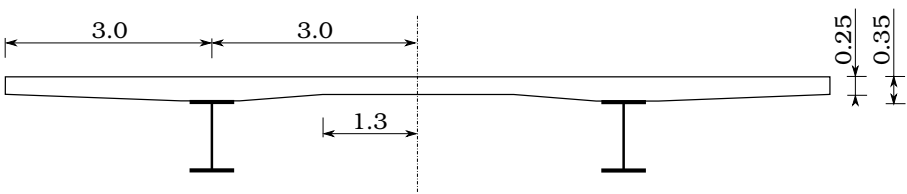

reinforcement ratio of hogging section $=2.0 \%$ reinforcement ratio of sagging section $=1.0 \%$

(a)

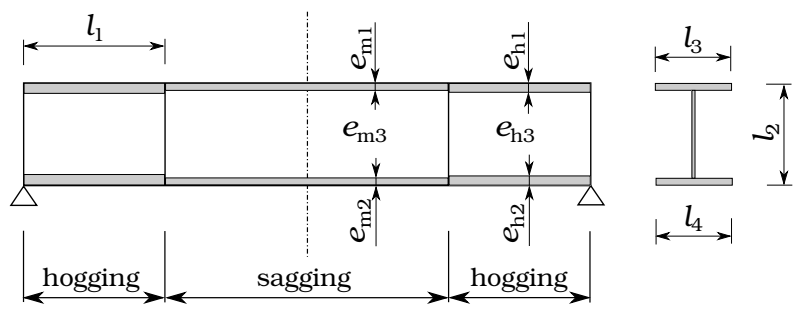

(b)

Figure 3: (a) Decks cross-section (values in meters), (b) girders plates thicknesses and dimensions (values in Table 3).

\begin{tabular}{|c|c|c|c|c|c|c|c|c|c|c|c|c|c|c|c|}
\hline $\begin{array}{l}\text { Case } \\
\text { label }\end{array}$ & $\begin{array}{c}H \\
{[\mathbf{m}]}\end{array}$ & $\begin{array}{c}L \\
{[\mathbf{m}]}\end{array}$ & $\begin{array}{c}D \\
{[\mathbf{m}]}\end{array}$ & $\begin{array}{c}N_{S d} \\
{[\mathbf{M N}]}\end{array}$ & $\begin{array}{l}\Delta_{y} \\
{[\mathbf{m}]}\end{array}$ & $\begin{array}{l}\Delta_{d} \\
{[\mathbf{m}]}\end{array}$ & $\mu$ & $\begin{array}{c}\text { Stability } \\
\text { index }\end{array}$ & $\begin{array}{l}\xi_{e q} \\
{[\%]}\end{array}$ & $\begin{array}{c}T_{\text {eff }} \\
{[\mathbf{s}]}\end{array}$ & $\begin{array}{c}M_{S d} \\
{[\mathbf{M N m}]}\end{array}$ & $\begin{array}{l}\text { No. of } \\
\text { long. } \\
\text { rebars }\end{array}$ & $\begin{array}{l}\text { Long. } \\
\text { reinforc. } \\
\text { ratio } \\
{[\%]}\end{array}$ & $\begin{array}{c}M_{R d} \\
{[\mathbf{M N m}]}\end{array}$ & $\begin{array}{c}\text { Stirrups } \\
\text { spacing } \\
{[\mathrm{cm}]}\end{array}$ \\
\hline H10L25 & 10.0 & 25.0 & 2.4 & -5.16 & 0.080 & 0.325 & 4.05 & 0.064 & 15.6 & 2.78 & 9.21 & 36 & $1.00^{* *}$ & 26.25 & 17.0 \\
\hline H10L50 & 10.0 & 50.0 & 2.4 & -8.78 & 0.080 & 0.325 & 4.05 & 0.098 & 15.6 & 2.78 & 17.81 & 36 & $1.00^{* *}$ & 29.26 & 14.0 \\
\hline H10L75 & 10.0 & 75.0 & 2.4 & -12.80 & 0.080 & 0.325 & 4.05 & $0.127^{*}$ & 15.6 & 2.78 & 32.86 & 37 & 1.03 & 32.88 & 9.0 \\
\hline H15L25 & 15.0 & 25.0 & 2.4 & -5.73 & 0.176 & 0.355 & 2.02 & 0.076 & 12.1 & 2.78 & 15.79 & 36 & $1.00^{* *}$ & 26.74 & 18.0 \\
\hline H15L50 & 15.0 & 50.0 & 2.4 & -9.35 & 0.176 & 0.355 & 2.02 & $0.103^{*}$ & 12.1 & 2.78 & 31.75 & 41 & 1.14 & 32.33 & 13.0 \\
\hline H15L75 & 15.0 & 75.0 & 2.4 & -13.37 & 0.176 & 0.355 & 2.02 & 0.100 & 12.1 & 2.78 & 44.44 & 65 & 1.81 & 47.56 & 9.0 \\
\hline H30L25 & 30.0 & 25.0 & 2.4 & -7.43 & 0.682 & 0.670 & 0.98 & $0.177^{*}$ & 5.0 & 5.00 & 27.17 & 36 & $1.00^{* *}$ & 28.19 & 16.0 \\
\hline H30L50 & 30.0 & 50.0 & 2.4 & -11.05 & 0.682 & 0.670 & 0.98 & $0.178^{*}$ & 5.0 & 5.00 & 41.24 & 56 & 1.56 & 41.56 & 11.0 \\
\hline H30L75 & 30.0 & 75.0 & 2.4 & -15.06 & 0.682 & 0.670 & 0.98 & $0.167^{*}$ & 5.0 & 5.00 & 60.08 & 90 & 2.50 & 60.46 & 9.0 \\
\hline
\end{tabular}

* $M_{S d}$ has been overestimated according to stability index higher than 0.1 [22].

** Minimum amount of reinforcement required by the standard [22].

Table 4: Definition of cases of studies, case labels and pier properties.

get the desired elastic or ductile behaviours, evaluated starting from the elastic displacement $\Delta_{y}$, which accounts for the contribution of the strain penetration [22]. Taking into account the displacement response spectrum, suitably reduced on the basis of the equivalent viscous damping ratio $\xi_{e q}$ of the system accounting for the energy dissipation by yielding [18], the effective (i.e. inelastic) period of the pier $T_{\text {eff }}$ is determined. The inelastic period of the system provides the secant stiffness from which stress resultants can be determined in order to perform conventional safety verifications. The adopted procedure, which accounts for the bidirectional nature of the seismic action, comply with code [22] requirements in terms of reinforcement detailing, stability conditions and hierarchy principles. The approach is repeated to design all piers of the analysed bridges, considering r.c. piers with circular cross-section of diameter $D=2.4 \mathrm{~m}$ and assuming a concrete grade C35/45. Furthermore, reinforcements of steel grade B450C and diameter of 40 and $22 \mathrm{~mm}$ are used for the longitudinal and transverse reinforcements, respectively. Table 4 reports details of the design procedure in addition to already defined quantities, being $N_{S d}$ the design axial force, and $M_{S d}$ and $M_{R d}$ the design bending moment and the bending moment resistance, respectively.

It is worth noting that the standard [22] requires a minimum longitudinal reinforcement ratio of $1 \%$ and dictates increasing the design bending moment if the stability index exceeds 0.1 in order to account for second order effects. It is worth mentioning that for some investigated bridges, piers have been oversized to comply with code requirements, with consequences on the relevant seismic behaviour with respect to the expected one. 


\begin{tabular}{cccccccc}
$\begin{array}{c}\text { Case } \\
\text { label }\end{array}$ & $\begin{array}{c}N_{S d} \\
{[\mathbf{M N}]}\end{array}$ & $\begin{array}{c}M_{R d} \\
{[\mathbf{M N m}]}\end{array}$ & $\begin{array}{c}V_{R d} \\
{[\mathbf{M N}]}\end{array}$ & Layout & $\begin{array}{c}\varnothing_{p} \\
{[\mathbf{m}]}\end{array}$ & $s / \varnothing_{p}$ & $\begin{array}{c}\text { Piles length } \\
{[\mathbf{m}]}\end{array}$ \\
\hline H10L25 & -5.16 & 26.25 & 2.63 & $2 \times 2$ & 1.2 & 3.0 & 31.0 \\
H10L50 & -8.78 & 29.26 & 2.93 & $2 \times 2$ & 1.2 & 3.0 & 35.0 \\
H10L75 & -12.80 & 32.88 & 3.29 & $2 \times 2$ & 1.2 & 3.0 & 45.0 \\
H15L25 & -5.73 & 26.74 & 1.78 & $3 \times 2$ & 1.2 & 3.0 & 31.0 \\
H15L50 & -9.35 & 32.33 & 2.16 & $3 \times 2$ & 1.2 & 3.0 & 35.0 \\
H15L75 & -13.37 & 47.56 & 3.17 & $3 \times 2$ & 1.2 & 3.0 & 40.0 \\
H30L25 & -7.43 & 28.19 & 0.94 & $3 \times 2$ & 1.5 & 3.0 & 32.0 \\
H30L50 & -11.05 & 41.56 & 1.39 & $3 \times 2$ & 1.5 & 3.0 & 32.0 \\
H30L75 & -15.06 & 60.46 & 2.02 & $3 \times 2$ & 1.5 & 3.0 & 40.0
\end{tabular}

Table 5: Design action effects at the foundation level and pile foundations dimensions.

\subsection{Pile foundations}

Pile foundations are designed according to hierarchy principles, following indications available in [22], relevant to structures designed through non-linear analyses. A $2 \times 2$ square piles layout is considered for $H=10 \mathrm{~m}$ bridges, while a $3 \times 2$ layout (with the line of 3 piles oriented in the bridge transverse direction) is assumed for $H=15$ and $H=30 \mathrm{~m}$ bridges. Piles diameter $\varnothing_{p}$, length and spacing $s$ are calculated for each bridge with standard methodologies for cohesive soils. For soft normally consolidated clay deposits, the undrained strength $C_{u}$ is assumed to increase linearly with the vertical lithostatic stress, while for the geological bedrock (constituted by over consolidated clay) $C_{u}=$ $600 \mathrm{kPa}$ is considered. The actions at the base of piers result from the above design methodology. Foundation parameters are summarized in Table 5. Piles Young's modulus $E_{p}=30.0 \mathrm{GPa}$ and density $\rho_{p}=2.5 \mathrm{t} / \mathrm{m}^{3}$ are considered, and different pile rake angles $\theta$ are hypotheses to address the relevant contribution to the superstructure response. In details, $\theta=0^{\circ}$ (vertical piles), $5^{\circ}, 10^{\circ}$ and $15^{\circ}$ are considered, according to the layouts of Figure 4.

\section{Methodology}

The seismic transverse behaviour of the bridges is studied exploiting advantages deriving from the deck restraints at dynamic conditions. Single bridge piers, with the tributary deck masses, are considered and suitably modelled to account for both the non-linear mechanical behaviour and the SSI. The response of the soil-foundation-pier system can be considered representative of the overall behaviour of inner piers of the viaducts, slightly affected by boundary effects at the abutments. In detail, the non-linear elastic and damping properties of the pier are modelled through a lumped rotational spring $\left(K_{\phi}\right)$ and dashpot $\left(C_{\phi}\right)$ at the base of the pier. The response of the system is estimated through the substructure approach [19] where the compliance of the soil-foundation system is represented by frequency-dependent impedance functions.

\subsection{Model of the soil-foundation-pier system}

By considering the in-plane response of the soil-foundation-pier system, the whole problem is described as the three degree-of-freedom system depicted in Figure 5, with $u_{F}$ and $\varphi_{F}$ being the translation and rotation of the foundation, $\varphi_{S}$ the relative rotation of the pier with respect to the foundation, and $u_{g}$ and $\varphi_{g}$ the translational and rotational Foundation Input Motion (FIM), namely the motion experienced by the foundation as a consequence of the incident seismic waves. The latter are determined from a kinematic interaction analysis in the spirit of the sub-structuring approach. It 


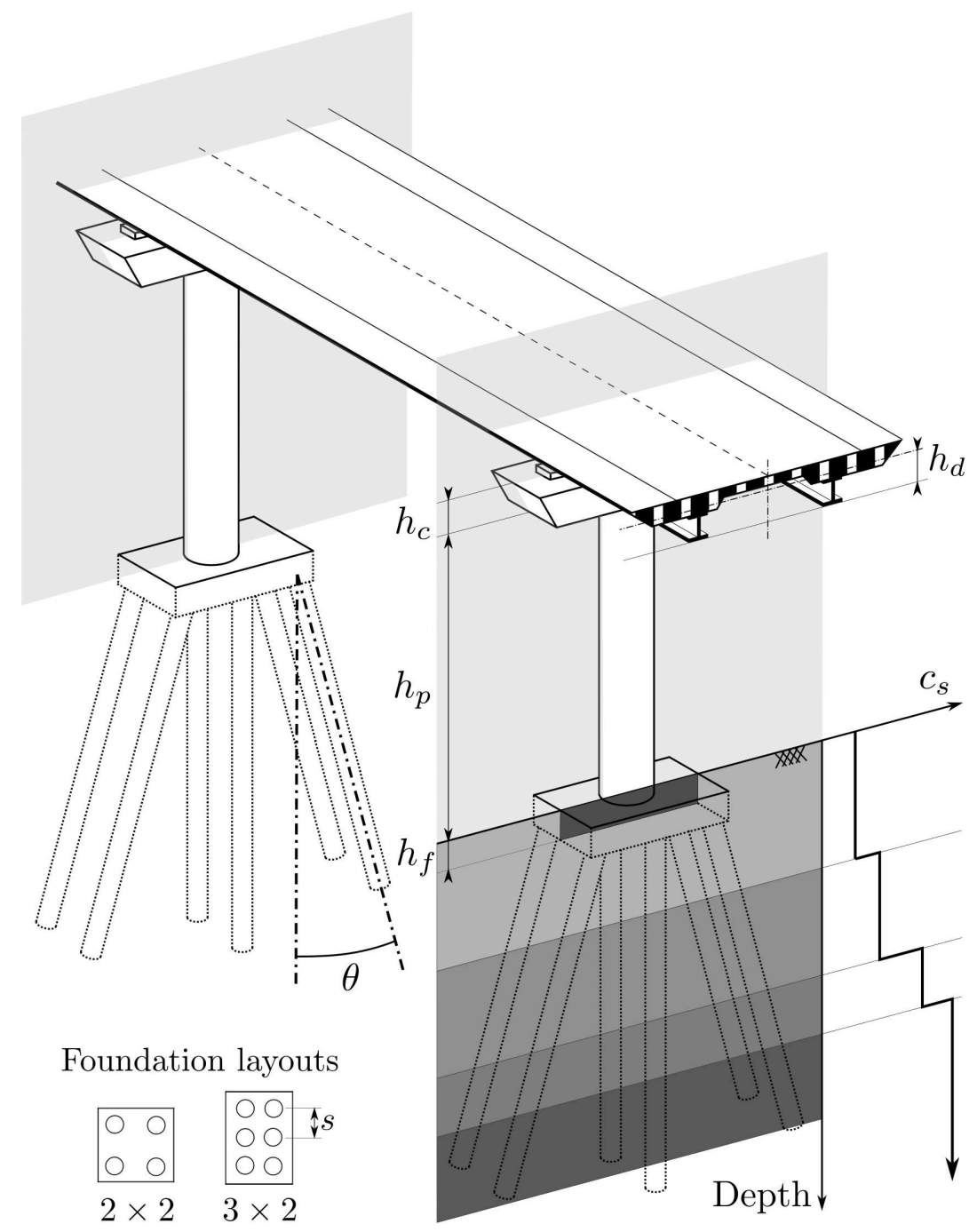

Figure 4: Soil-foundation-superstructure system and foundation layouts.

is worth noting that, by assuming pile layouts characterised by two symmetry axes and by referring the impedance matrix of the soil-foundation systems to the centroids of the pile configuration at the level of the pile head, the vertical degree-of-freedom is uncoupled from the horizontal and rotational ones and is not included in the formulation. Thus, the significant components of the soil-foundation impedance matrix are the horizontal, rotational and coupled roto-translational terms, represented in the Compliant-Base (CB) model of the pier in Figure 5 through linear frequency dependent viscoelastic Kelvin-Voigt's models at the foundation-superstructure interface. Fixed-Base (FB) models will be also considered, whose results will be used to address and discuss the significance of the SSI effects.

In Figure $5, m_{d}$ and $m_{c}$ are the masses of bridge deck portion belonging to the generic pier, and of the pier bent cap, respectively. Furthermore, $m_{p}$ and $m_{f}$ are the masses of the pier and the pile cap, and $I_{d}, I_{c}$ and $I_{f}$ are the mass moments of inertia of the deck and the bent cap, and of the pile cap, respectively. Finally, $h_{d}, h_{c}, h_{p}$ and $h_{f}$ are dimensions necessary to account for the position of the mass centroids of the deck, the bent cap and the pile cap. The FIMs are obtained starting from the free-field motion and the kinematic interaction factors of the soil-foundation system, resulting from the analysis of the soil-foundation sub-domain subjected to propagating harmonic shear waves in the soil. Parameters of the structural models representative of all the superstructures considered in this study are reported on Table 6 . This table also presents the natural $T_{n}$ and effective $T_{\text {eff }}$ periods of each superstructure, together with the natural period $T_{n}^{*}$ resulting from relaxing the requirement 


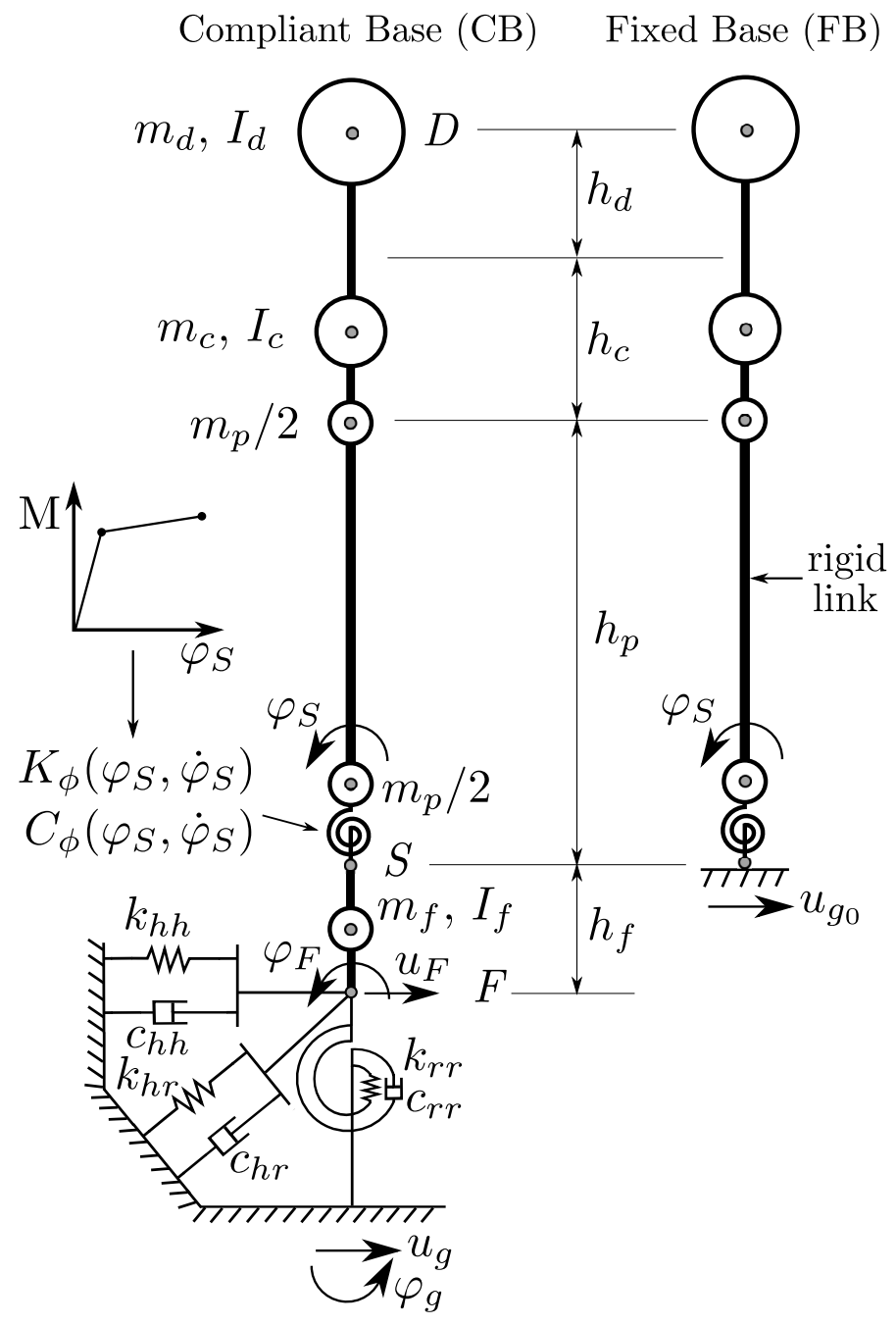

Figure 5: Compliant-Base (CB) and Fixed-Base (FB) models of the in-plane dynamic response of the soil-foundation-pier systems.

over minimum reinforcement content and stability index established by [22].

\subsection{Impedance functions and kinematic interaction factors}

Impedance functions and kinematic interaction factors of the pile foundations were computed, for reference and for comparison, using two different frequency-domain models: a) the Winkler-type model developed by Dezi et al. [28], and b) the boundary element-finite element model developed by Padrón et al. [29]. Although some differences between models appear in the mentioned functions, the differences observed later in terms of ductility demand are remarkably negligible. Thus, only results obtained using impedance functions and kinematic interaction factors computed with the second model are presented here, but the conclusions of the analysis have been found to be independent of the chosen model.

According to the model by Padrón et al. [29], piles are modelled using FEM as beams according to the Bernoulli hypothesis, while each strata of the soil is modelled using BEM as a continuum, semi-infinite, isotropic, homogeneous, linear, viscoelastic medium. The pile cap is assumed to be rigid and not in contact with the surrounding soil. The embedment of the pile cap has been included in the model for completeness, although its influence is expected to be negligible. Figure 6 shows the discretization used for the soil.

Impedance functions and kinematic interaction factors corresponding to all pile layouts are pre- 
H10L25 H10L50 H10L75 H15L25 H15L50 H15L75 H30L25 H30L50 H30L75

\begin{tabular}{|c|c|c|c|c|c|c|c|c|c|}
\hline$m_{d}[\mathrm{t}]$ & 343.5 & 712.5 & 1122.3 & 343.5 & 712.5 & 1122.3 & 343.5 & 712.5 & 1122.3 \\
\hline$I_{d} \quad\left[\begin{array}{ll}\mathrm{t} \mathrm{m}^{2}\end{array}\right]$ & 2906.4 & 6585.3 & 11933.3 & 2906.4 & 6585.3 & 11933.3 & 2906.4 & 6585.3 & 11933.3 \\
\hline$h_{d} \quad[\mathrm{~m}]$ & 0.97 & 1.53 & 2.08 & 0.97 & 1.53 & 2.08 & 0.97 & 1.53 & 2.08 \\
\hline$m_{c}[\mathrm{t}]$ & 88.3 & 88.3 & 88.3 & 88.3 & 88.3 & 88.3 & 88.3 & 88.3 & 88.3 \\
\hline$I_{c} \quad\left[\begin{array}{ll}\mathrm{t} \mathrm{m}^{2} & \end{array}\right.$ & 426.6 & 426.6 & 426.6 & 426.6 & 426.6 & 426.6 & 426.6 & 426.6 & 426.6 \\
\hline$h_{c} \quad[\mathrm{~m}]$ & 1.80 & 1.80 & 1.80 & 1.80 & 1.80 & 1.80 & 1.80 & 1.80 & 1.80 \\
\hline$m_{p} \quad[\mathrm{t}]$ & 94.5 & 94.5 & 94.5 & 152.18 & 152.18 & 152.18 & 325.1 & 325.1 & 325.1 \\
\hline $\begin{array}{ll}h_{p} & {[\mathrm{~m}]}\end{array}$ & 8.20 & 8.20 & 8.20 & 13.20 & 13.20 & 13.20 & 28.20 & 28.20 & 28.20 \\
\hline$m_{f}[\mathrm{t}]$ & 78.4 & 78.4 & 78.4 & 257.6 & 257.6 & 257.6 & 503.1 & 503.1 & 503.1 \\
\hline$I_{f} \quad\left[\mathrm{t} \mathrm{m}^{2}\right]$ & 211.4 & 211.4 & 211.4 & 1902.8 & 1902.8 & 1902.8 & 5806.9 & 5806.9 & 5806.9 \\
\hline$h_{f} \quad[\mathrm{~m}]$ & 1.00 & 1.00 & 1.00 & 2.00 & 2.00 & 2.00 & 2.50 & 2.50 & 2.50 \\
\hline$[\mathrm{s}]$ & 0.71 & 0.96 & 1.18 & 1.27 & 1.62 & 1.75 & 3.69 & 4.13 & 4.29 \\
\hline$T_{n}^{*}$ & 1.08 & 1.20 & 1.28 & 1.62 & 1.73 & 1.83 & 4.28 & 4.56 & 4.74 \\
\hline$T_{\text {eff }}[\mathrm{s}]$ & 2.78 & 2.78 & 2.78 & 2.78 & 2.78 & 2.78 & 5.00 & 5.00 & 5.00 \\
\hline
\end{tabular}

Table 6: Set of parameters defining the different FB and CB systems (see Figure 5) used to model the superstructure considered for each case of analysis.

sented in Figures 7 (solid lines) and 8, respectively. In both cases, the functions corresponding to the different pile inclinations are presented in different columns. The stratified nature of the investigated soil profile is clearly evident in the impedance functions through the cut-off frequencies that can be observed in the damping functions, and the multiple resonance frequencies appearing in the stiffness functions in the frequency range $0-2 \mathrm{~Hz}$. A significant increase in stiffness and damping capacity with number of piles and pile diameter can also be observed for all rake angles. Also, as expected, the horizontal stiffness is shown to increase with rake angle while rocking stiffnesses decrease only slightly with pile inclination. Regarding the kinematic interaction factors (see Figure 8), translational factors tend to decrease with the rake angle, while rotation factors experiment a significant increase. This induced rotation is responsible for structural anti-phase displacements and accelerations, with respect to those induced by translation, and its effects on linear systems have been already addressed and discussed in $[16,17]$. In order to help interpreting the relevance of the trends shown in Figure 8, the normalized mean Fourier amplitude spectrum of the selected ground motions (Table 2) is also included as a grey line in the first plot. It shows that the energy content of ground motions is mainly concentrated between 0 and $7 \mathrm{~Hz}$, range within which the variations in the kinematic interaction factors (and most importantly, the rotational factor) are not negligible.

\subsection{Lumped Parameter Models}

Simulations in time domain are mandatory if the non-linear behaviour of the superstructure is going to be analysed. The problem formulation in the time domain requires a suitable strategy to account for the frequency-dependent behaviour of the soil-foundation system. LPMs can be used to approximate impedances of the soil-foundation system in a selected frequency range of interest [30] even though they lead to some loss of precision. The accuracy of an LPM in reproducing the dynamic behaviour of the soil-foundation system depends on its configuration, formulation and number degrees of freedom.

A particular LPM scheme, whose applicability in similar structures has been previously studied [31], has been developed by some of the authors [32]. It is constituted by the two degree-offreedom system represented in Figure 9, and it is characterized by a translational mass $m_{h}$ and a mass moment of inertia $I_{r}$ at the foundation-structure interface, connected to the soil through translational and rotational pairs of constant springs and dashpots $k_{h}, c_{h}, k_{r}$ and $c_{r}$. Furthermore, 


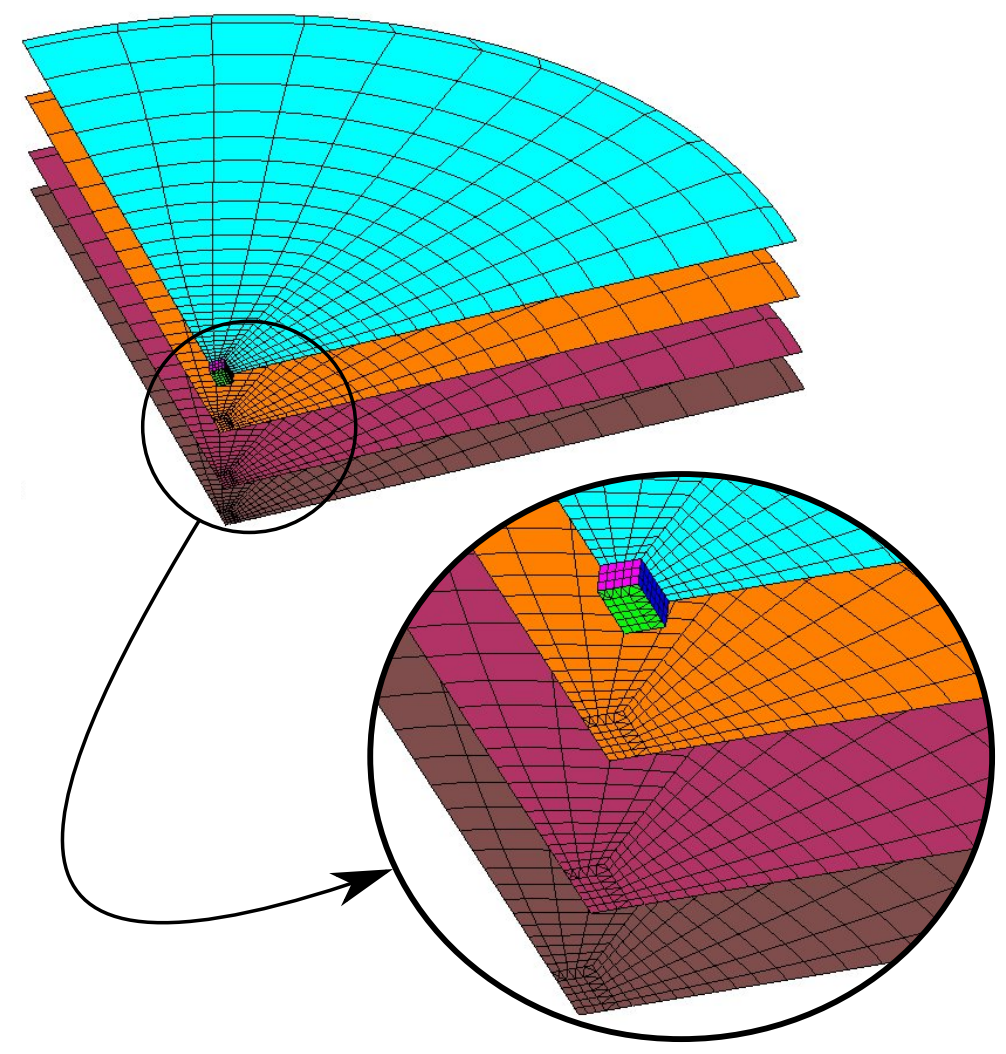

Figure 6: Example of BEM discretization for the computation of impedance functions and kinematic interaction factors (only a quarter of the geometry is shown).

the translational mass $m_{h}$ is connected to an additional eccentric translational mass $m_{t}$, spring $k_{t}$ and dashpot $c_{t}$ through a rigid massless link of lengths $h_{3}, h_{2}$ and $h_{1}$, respectively. All the constant values of the LPM are obtained through a least square fitting procedure of the LPM response to the reference impedance functions. The fitting procedure has been constrained by positive values of masses, dashpots and springs, and leaving the possibility of negative values for link lengths. It can be shown that the stiffnesses represented in Figure 9 can be expressed as

$$
\begin{aligned}
\operatorname{Real}\left[K_{h h}\right] & =k_{h h}(\omega) \approx k_{h}+k_{t}-\omega^{2}\left(m_{h}+m_{t}\right) \\
\operatorname{Imag}\left[K_{h h}\right] & =\omega c_{h h}(\omega) \approx \omega\left(c_{h}+c_{t}\right) \\
\operatorname{Real}\left[K_{r r}\right] & =k_{r r}(\omega) \approx k_{r}+k_{t} h_{1}^{2}-\omega^{2}\left(I_{r}+m_{t} h_{3}^{2}\right) \\
\operatorname{Imag}\left[K_{r r}\right] & =\omega c_{r r}(\omega) \approx \omega\left(c_{r}+c_{t} h_{2}^{2}\right) \\
\operatorname{Real}\left[K_{h r}\right] & =k_{h r}(\omega) \approx k_{t} h_{1}-\omega^{2} m_{t} h_{3} \\
\operatorname{Imag}\left[K_{h r}\right] & =\omega c_{h r}(\omega) \approx \omega c_{t} h_{2}
\end{aligned}
$$

where all real and imaginary terms are parabolic and linear functions of $\omega$, respectively.

LPM impedances resulting from the fitting procedure are shown in dashed line in Figure 7 superposed to the BEM-FEM impedances for a qualitative comparison. The fitting frequency range has been assumed to be $0-5 \mathrm{~Hz}$. The latter is assumed to be sufficiently wide, given that the maximum fundamental frequency of the investigated bridges (in the elastic range) is $1.41 \mathrm{~Hz}$ (for the H10L25 case) and that results achieved in [31] demonstrate that an optimization of impedance functions nearby the fundamental structural frequency is sufficient to achieve accurate results for this type of structures. As shown in Figure 7, the derived LPMs are not able to reproduce exactly all the trends captured by the original impedance functions. However, these differences will be shown to have no impact whatsoever on the results of interest in this study (see Section 4.1). 

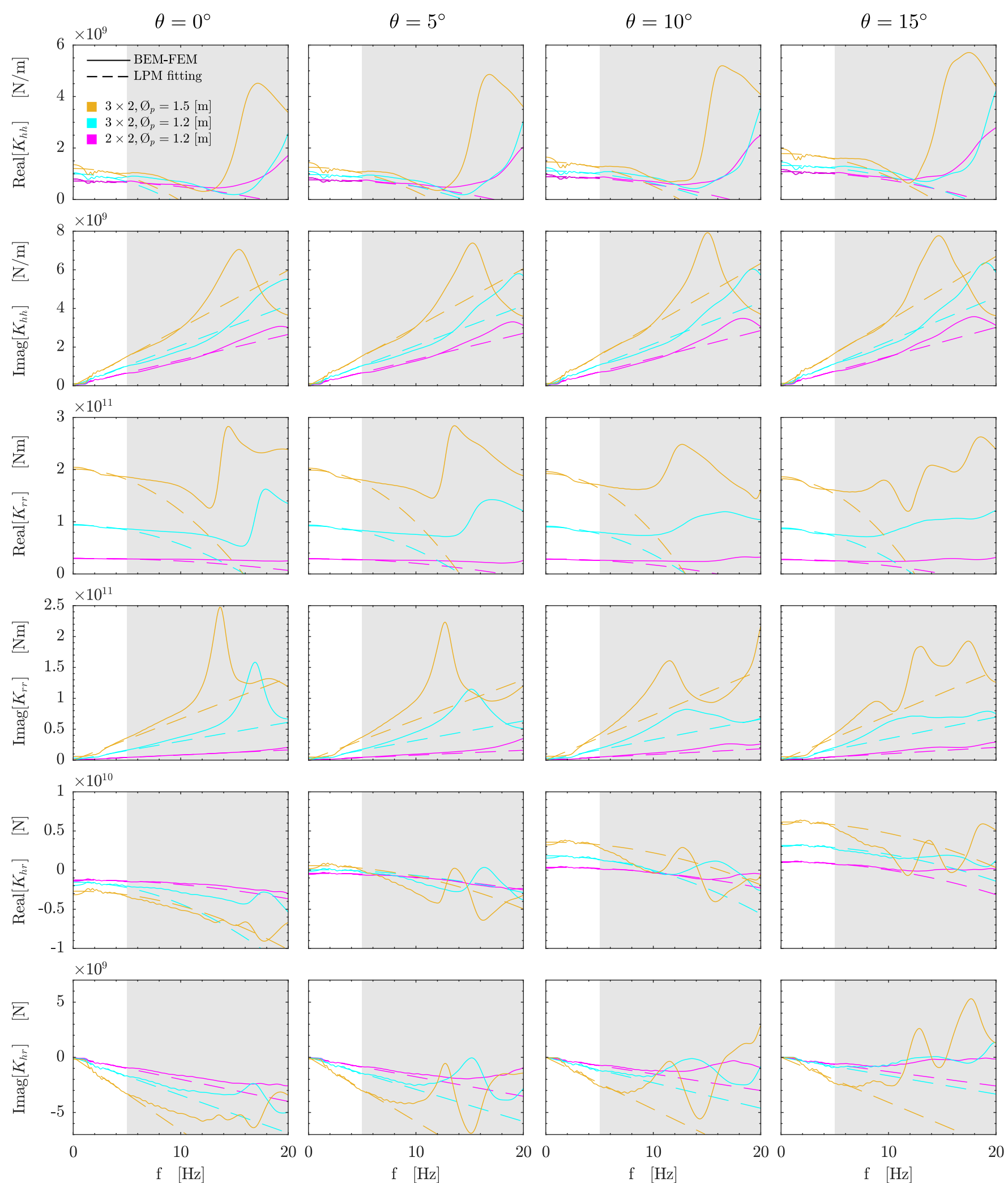

Figure 7: Computed and fitted impedance functions for all foundations layouts. 

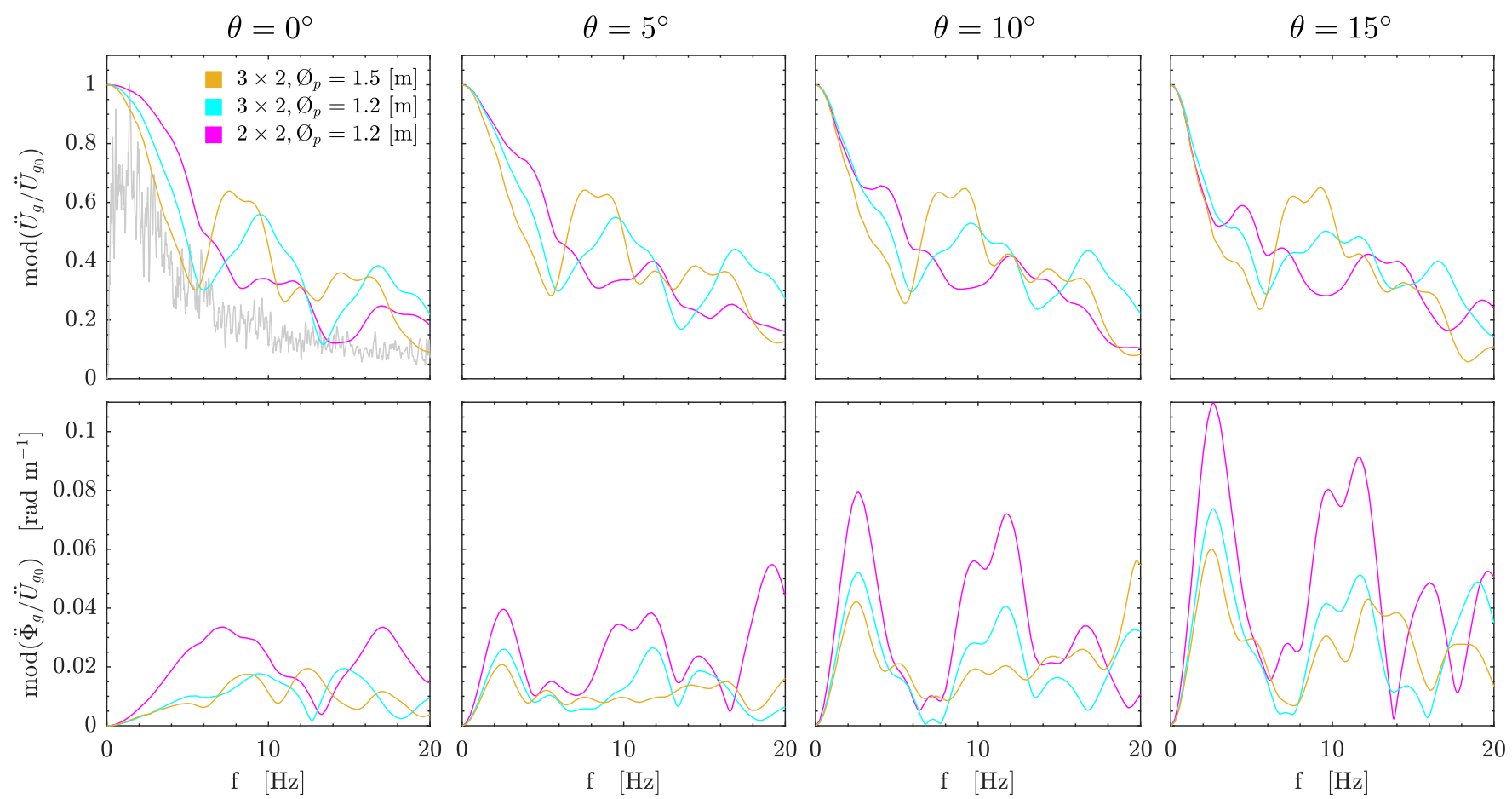

Figure 8: Computed kinematic interaction factors of pile foundations (the gray line represents normalized mean Fourier amplitude spectrum of the selected ground motions).
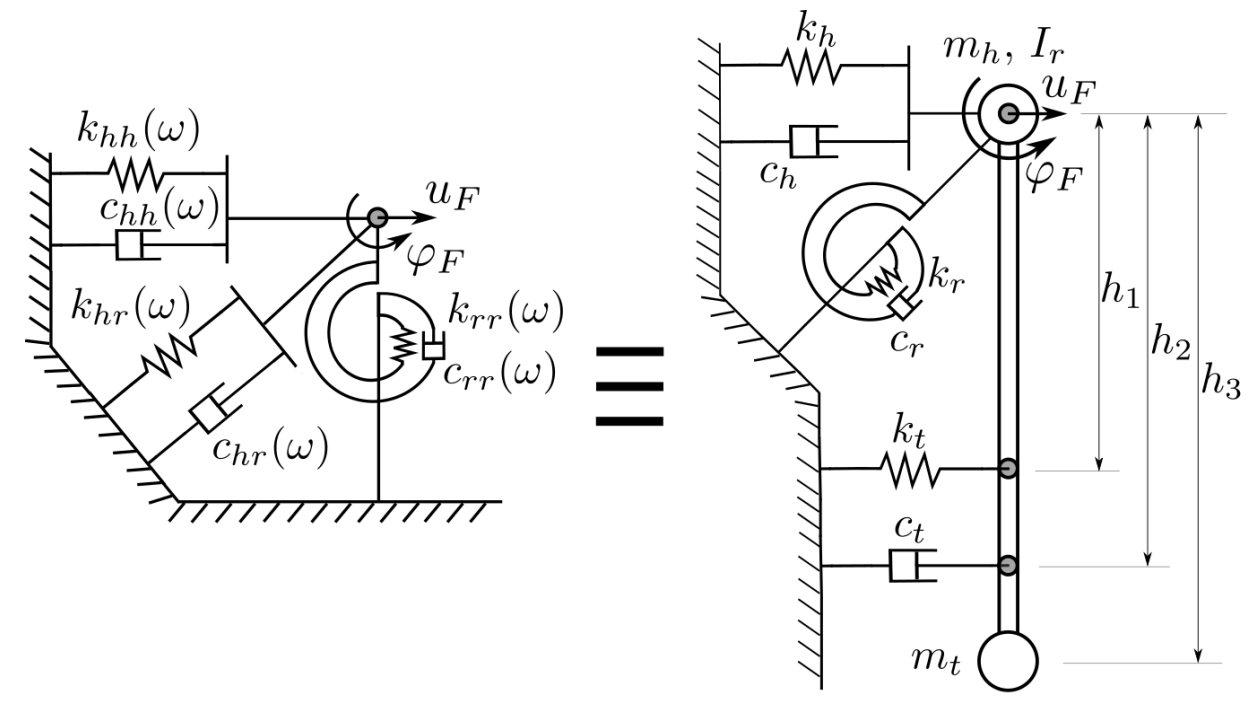

Figure 9: Scheme of the LPM adopted in the study [32]. 


\subsection{Equations of motion}

The three equations of motion of the $\mathrm{CB}$ system, neglecting second-order effects (i.e. making the hypothesis of small displacements), describe the moment equilibrium of the pier, and the horizontal and the moment equilibrium of the superstructure-foundation system, respectively:

$$
\mathbf{M}^{\prime}\left[\begin{array}{c}
\ddot{\varphi}_{S} \\
\ddot{u}_{F} \\
\ddot{\varphi}_{F}
\end{array}\right]+\mathbf{C}\left[\begin{array}{c}
\dot{\varphi}_{S} \\
\dot{u}_{F} \\
\dot{\varphi}_{F}
\end{array}\right]+\mathbf{K}\left[\begin{array}{c}
\varphi_{S} \\
u_{F} \\
\varphi_{F}
\end{array}\right]+\mathbf{K}_{\phi}\left[\begin{array}{c}
\dot{\varphi}_{S} \\
\varphi_{S}
\end{array}\right]=-\mathbf{M a}\left[\begin{array}{c}
\ddot{u}_{g} \\
\ddot{\varphi}_{g}
\end{array}\right]
$$

being:

$$
\begin{aligned}
\mathbf{M}^{\prime} & =\left[\begin{array}{ccc}
m_{11} & m_{12} & m_{13} \\
m_{12} & m_{22}+m_{h}+m_{t} & m_{23}+m_{t} h_{3} \\
m_{13} & m_{23}+m_{t} h_{3} & m_{33}+I_{r}+m_{t} h_{3}^{2}
\end{array}\right] \\
\mathbf{C} & =\left[\begin{array}{ccc}
0 & 0 & 0 \\
0 & c_{h}+c_{t} & c_{t} h_{2} \\
0 & c_{t} h_{2} & c_{r}+c_{t} h_{2}^{2}
\end{array}\right] \\
\mathbf{K} & =\left[\begin{array}{ccc}
0 & 0 & 0 \\
0 & k_{h}+k_{t} & k_{t} h_{1} \\
0 & k_{t} h_{1} & k_{r}+k_{t} h_{1}^{2}
\end{array}\right] \\
\mathbf{K}_{\phi} & =\left[\begin{array}{cc}
C_{\phi} & K_{\phi} \\
0 & 0 \\
0 & 0
\end{array}\right] \\
\mathbf{M} & =\left[\begin{array}{lll}
m_{11} & m_{12} & m_{13} \\
m_{12} & m_{22} & m_{23} \\
m_{13} & m_{23} & m_{33}
\end{array}\right] \\
\mathbf{a} & =\left[\begin{array}{ll}
0 & 0 \\
1 & 0 \\
0 & 1
\end{array}\right]
\end{aligned}
$$

where mass matrix coefficients are:

$$
\begin{aligned}
m_{11}= & \left(h_{p}+h_{c}+h_{d}\right)^{2} m_{d}+I_{d}+\left(h_{p}+\frac{h_{c}}{2}\right)^{2} m_{c}+I_{c}+h_{p}^{2} \frac{m_{p}}{2} \\
m_{12}= & \left(h_{p}+h_{c}+h_{d}\right) m_{d}+\left(h_{p}+\frac{h_{c}}{2}\right) m_{c}+h_{p} \frac{m_{p}}{2} \\
m_{13}= & \left(h_{p}+h_{c}+h_{d}\right)\left(h_{f}+h_{p}+h_{c}+h_{d}\right) m_{d}+I_{d}+\left(h_{p}+\frac{h_{c}}{2}\right)\left(h_{f}+h_{p}+\frac{h_{c}}{2}\right) m_{c}+I_{c}+ \\
& +h_{p}\left(h_{f}+h_{p}\right) \frac{m_{p}}{2} \\
m_{22}= & m_{d}+m_{c}+m_{p}+m_{f} \\
m_{23}= & \left(h_{f}+h_{p}+h_{c}+h_{d}\right) m_{d}+\left(h_{f}+h_{p}+\frac{h_{c}}{2}\right) m_{c}+\left(h_{f}+h_{p}\right) \frac{m_{p}}{2}+h_{f} \frac{m_{p}}{2}+\frac{h_{f}}{2} m_{f} \\
m_{33}= & \left(h_{f}+h_{p}+h_{c}+h_{d}\right)^{2} m_{d}+I_{d}+\left(h_{f}+h_{p}+\frac{h_{c}}{2}\right)^{2} m_{c}+I_{c}+\left(h_{f}+h_{p}\right)^{2} \frac{m_{p}}{2}+h_{f}^{2} \frac{m_{p}}{2}+ \\
& +\left(\frac{h_{f}}{2}\right)^{2} m_{f}+I_{f}
\end{aligned}
$$




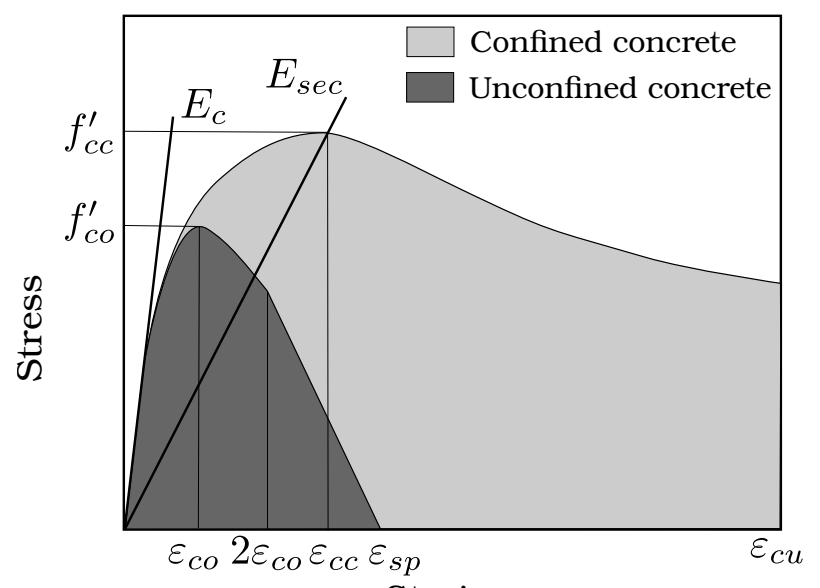

Strain

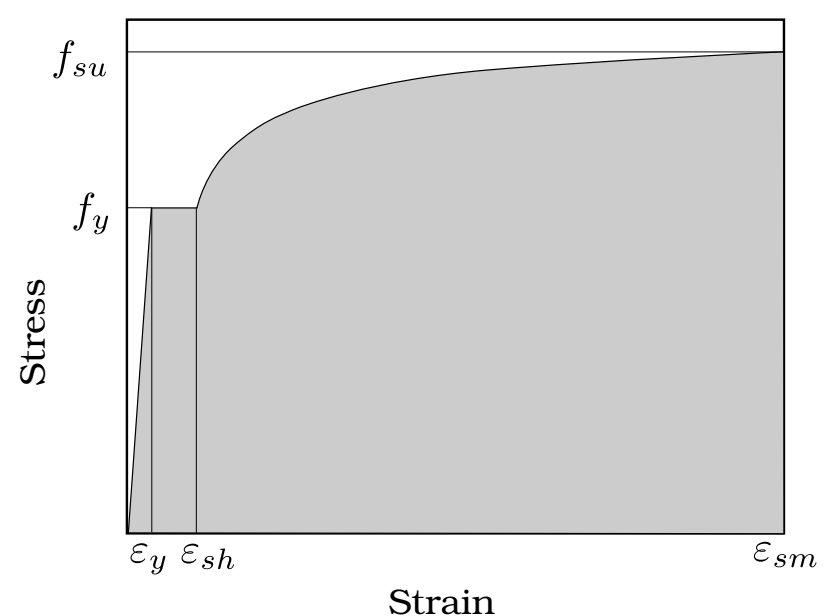

Figure 10: Mander constitutive law for the confined and unconfined concrete [35] and the King law [36] for rebars.

Notice that terms $C_{\phi}$ and $K_{\phi}$, accounting for the system non-linearities, have been suitably decoupled from the linear contributions in Equations (2) and (3d) to allow for an ease implementation and control of the solution, using the central differences time-stepping integration method [33]. Finally, $C_{\phi}$ is computed to obtain a $5 \%$ tangent stiffness proportional viscous damping in correspondence of the fundamental elastic period of the superstructures.

The FB model is a one degree-of-freedom system, expressed in terms of the pier relative rotation $\varphi_{S}$. Its governing equation is the moment equilibrium, i.e. the first equation of the system presented in Equation (2). In FB models, no kinematic interaction is considered, i.e. the input signal coincides with the scaled horizontal free-field ground motion $\left(u_{g 0}\right)$ as shown in Figure 5.

\subsection{Moment-curvature-chord rotation relationships}

The moment-curvature constitutive relationship that characterises the non-linear behaviour of the piers base cross-section is obtained through the CUMBIA software [34] adopting the Mander constitutive law for the confined and unconfined concrete [35] and King law [36] for rebars (Figure 10).

In details, the unconfined concrete constitutive law is evaluated following indications of EC8-2 [22] assuming the strain at maximum strength $\varepsilon_{c o}$ and the maximum strain $\varepsilon_{s p}$ equal to 0.002 and 0.0067 , respectively. As for the maximum cylindrical compressive strength $f_{c o}^{\prime}$, the mean expected value for the concrete grade C35/45 is used, corresponding to $45.5 \mathrm{MPa}$, according to [18]. Furthermore, an initial elastic modulus $E_{c}$ equal to $33.73 \mathrm{GPa}$ is assumed. Constitutive laws representative of the 
H10L25

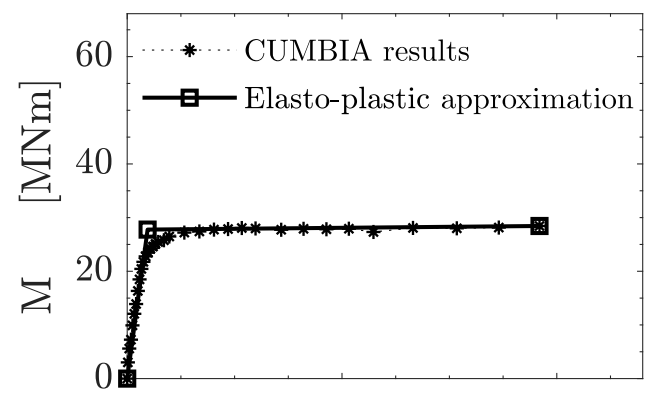

H15L25

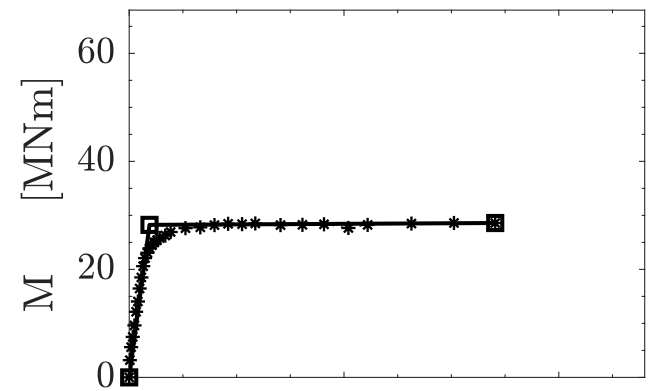

H30L25

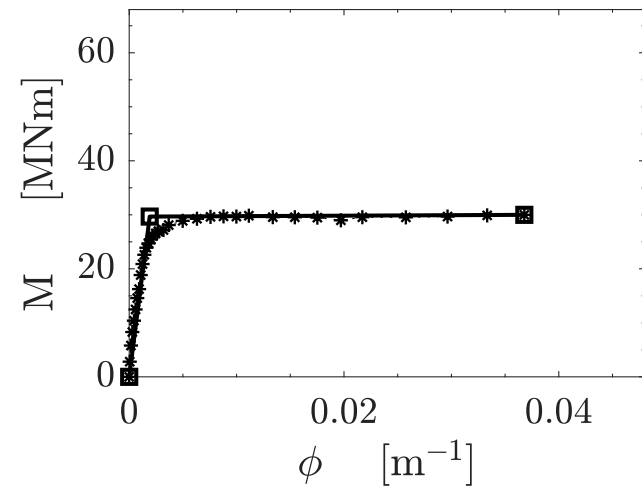

H10L50

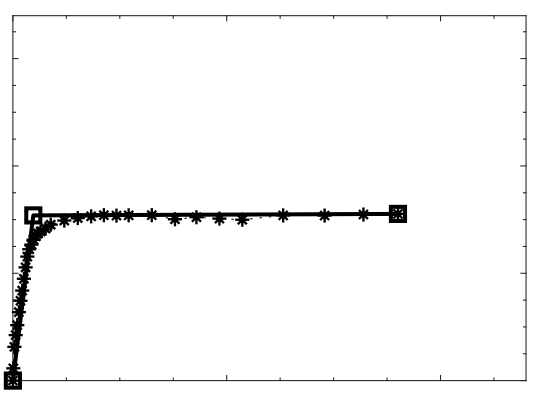

H15L50

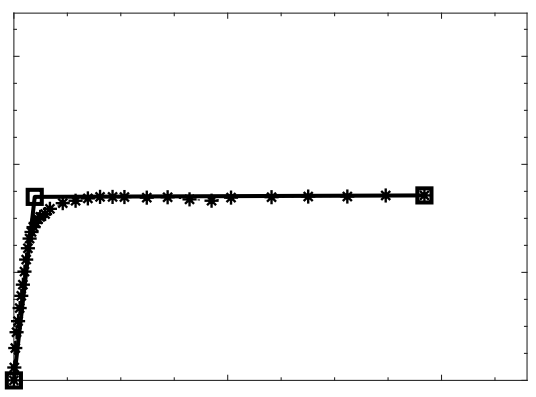

H30L50

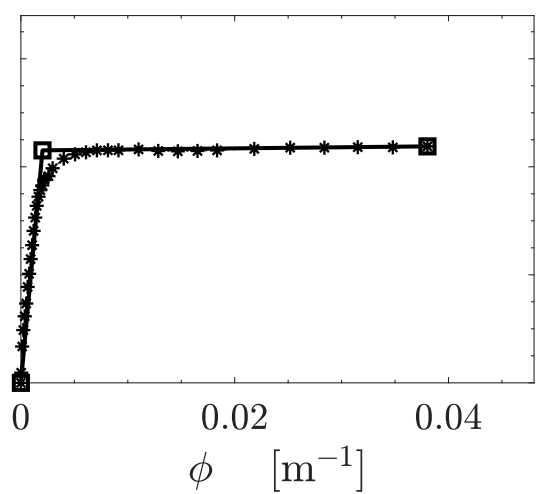

H10L75

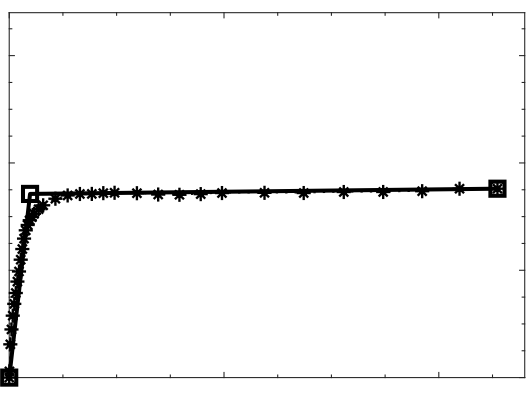

H15L75

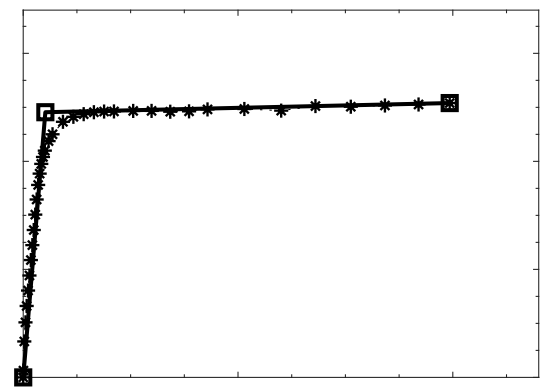

H30L75

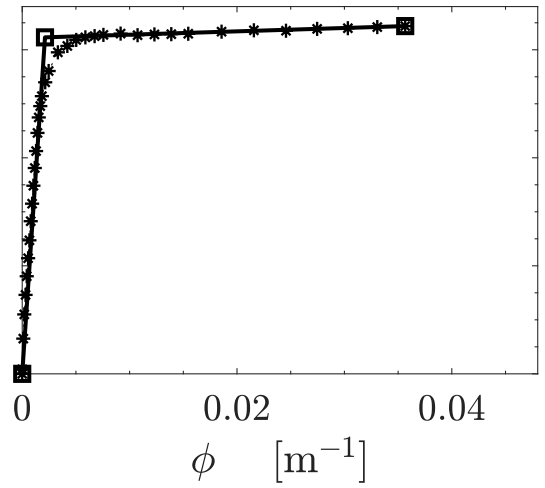

Figure 11: Moment-curvature constitutive relationships of piers cross-sections [34].

confined concrete of piers are determined taking into account the relevant contributions provided by stirrups [35, 37]. Expected mean yielding stresses of longitudinal $f_{y l}$ and transverse $f_{y t}$ reinforcements of grade B450C are assumed to be $495.0 \mathrm{MPa}$ and $450.0 \mathrm{MPa}$, respectively, according to indications provided in [18]; for both, considering the King's model, the strain hardening $\varepsilon_{s h}$ and the ultimate strain $\varepsilon_{s m}$ are assumed to be equal to 0.008 and 0.12 , respectively (Figure 10). Finally, the mean maximum tensile strength $f_{s u}$ is assumed equal to $668.0 \mathrm{MPa}$ while the Young's modulus $E_{s}$ is assumed to be $210.0 \mathrm{GPa}$.

Figure 11 shows the moment-curvature relationships obtained from the cross-sectional analyses for all the nine bridge piers, and the relevant elasto-plastic approximations [34]. The latter are used to determine the moment-chord rotation relationships, starting from the plastic hinge method proposed by Priestley et al. [38], i.e. considering an equivalent curvature distribution to facilitate the application of the moment area method to find the displacements in the member, from which the chord rotation is computed. The simplified distribution of curvatures assumes a constant plastic contribution over the equivalent plastic hinge length, which accounts for the strain penetration effect. This approach is widely adopted and suggested in the literature (e.g. [18, 22, 37]).

Table 7 summarises parameters of the constitutive bilinear moment-chord rotation laws of the 


\begin{tabular}{ccccc}
$\begin{array}{c}\text { Case } \\
\text { label }\end{array}$ & $\begin{array}{c}M_{y} \\
{[\mathbf{M N m}]}\end{array}$ & $\begin{array}{c}M_{u} \\
{[\mathbf{M N m}]}\end{array}$ & $\begin{array}{c}\varphi_{S y} \\
{[\mathbf{r a d}]}\end{array}$ & $\begin{array}{c}\varphi_{S u} \\
{[\mathbf{r a d}]}\end{array}$ \\
\hline H10L25 & $27.77(9.67)$ & $28.44(10.15)$ & $0.0063(0.0051)$ & $0.0454(0.0628)$ \\
H10L50 & $30.78(17.98)$ & $31.06(18.19)$ & $0.0064(0.0058)$ & $0.0429(0.0565)$ \\
H10L75 & $34.23(28.43)$ & $35.20(29.07)$ & $0.0065(0.0063)$ & $0.0531(0.0572)$ \\
H15L25 & $28.24(16.61)$ & $28.58(16.84)$ & $0.0095(0.0091)$ & $0.0549(0.0745)$ \\
H15L50 & $33.98(28.97)$ & $34.25(29.52)$ & $0.0098(0.0095)$ & $0.0612(0.0654)$ \\
H15L75 & $49.10(44.05)$ & $50.79(45.15)$ & $0.0103(0.0101)$ & $0.0635(0.0654)$ \\
H30L25 & $29.67(21.02)$ & $29.99(21.29)$ & $0.0191(0.0182)$ & $0.1038(0.1181)$ \\
H30L50 & $43.04(34.04)$ & $43.78(34.61)$ & $0.0202(0.0195)$ & $0.1077(0.1166)$ \\
H30L75 & $62.30(49.80)$ & $64.39(51.01)$ & $0.0212(0.0207)$ & $0.1027(0.1083)$
\end{tabular}

Table 7: Parameters for the plastic hinge modelling. Data within parenthesis refers to analyses disregarding code provisions concerning reinforcement detailing and stability issues.

lumped plastic hinges for the backbone construction, identified through the yielding $M_{y}$ and ultimate $M_{u}$ bending moments and the relevant yielding $\varphi_{S y}$ and ultimate $\varphi_{S u}$ rotations. Data within parenthesis refers to analyses disregarding code provisions concerning reinforcement detailing and stability issues. The hysteretic cyclic behaviour of the plastic hinges is defined adopting different models, considering and disregarding the stiffness degradation of reinforced concrete members due to cyclic loading. The stiffness degradation effect is taken into account through the Takeda's hysteresis model [20], while by using the bilinear hysteresis model no degradation effect is taken into account (Figure 12).

\subsection{Energy balance}

The input energy to the system is dissipated through different mechanisms. If the system is computed assuming FB hypothesis and the pier doesn't yields, all the input energy is dissipated by viscous damping in the superstructure. On the contrary, if the bridge is considered to be founded on an elastic foundation (CB model) and the pier yields, part of the input energy is dissipated by viscous damping in superstructure and foundation, and part is dissipated by the hysteretic cycles of the plastic hinge.

The contribution of each mechanism on the energy dissipation for a specific configuration provides useful information to understand the capability of the system to withstand the earthquake excitation.

The energy balance is computed pre-multiplying Equation (2) by the system velocity and integrating over the time $[33,39]$. The right-hand side of the resulting equation is the input energy to the system:

$$
E_{i n}=-\int_{0}^{t}\left[\begin{array}{lll}
\dot{\varphi}_{S} & \dot{u}_{F} & \dot{\varphi}_{F}
\end{array}\right] \mathbf{M a}\left[\begin{array}{c}
\ddot{u}_{g} \\
\ddot{\varphi}_{g}
\end{array}\right] \mathrm{d} \mathbf{t}
$$

The input energy is balanced during the motion by the kinetic energy $\left(E_{I}\right)$ due to the inertial forces, the energy dissipated by viscous damping in foundation $\left(E_{D_{\text {found }}}\right)$ and superstructure $\left(E_{D_{\text {super }}}\right)$, the recoverable strain energy in the foundation $\left(E_{K_{\text {found }}}\right)$ and the strain energy in the superstructure $\left(E_{K_{\text {super }}}\right)$ which includes both yielding and elastic components. All energy contributions are expressed in Equation (6). 
Takeda's hysteresis model

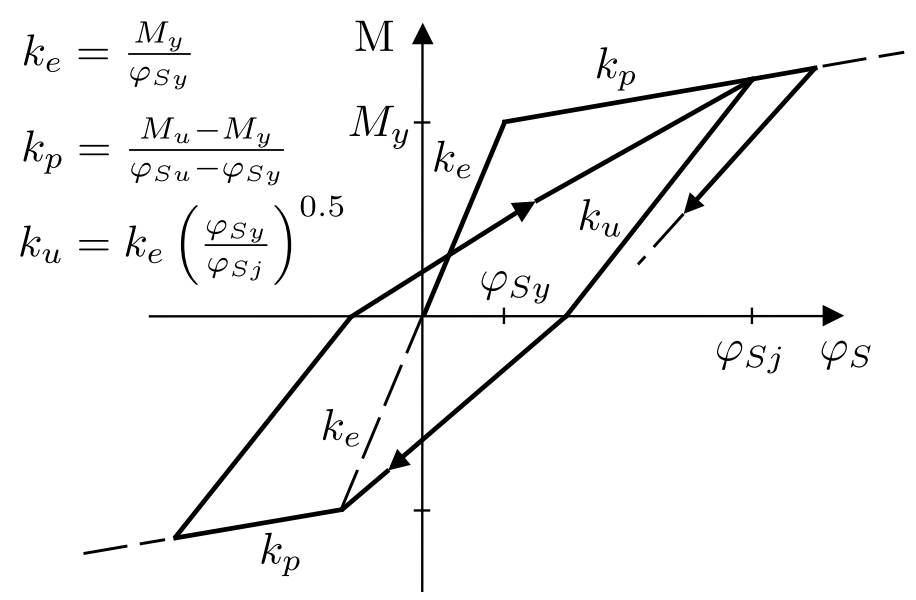

Biliniear hysteresis model

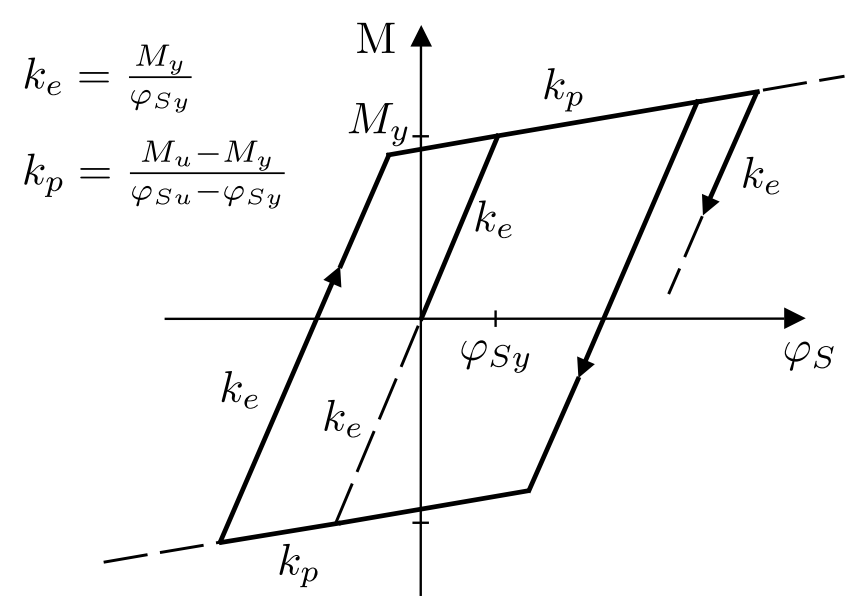

Figure 12: Hysteretic cyclic rules adopted to model the non-linear response of the plastic hinge.

$$
\begin{aligned}
E_{I} & =\int_{0}^{t}\left[\begin{array}{lll}
\dot{\varphi}_{S} & \dot{u}_{F} & \dot{\varphi}_{F}
\end{array}\right] \mathbf{M}^{\prime}\left[\begin{array}{c}
\ddot{\varphi}_{S} \\
\ddot{u}_{F} \\
\ddot{\varphi}_{F}
\end{array}\right] \mathrm{d} \mathbf{t} \\
E_{D_{\text {found }}} & =\int_{0}^{t}\left[\begin{array}{ll}
\dot{u}_{F} & \dot{\varphi}_{F}
\end{array}\right]\left[\begin{array}{cc}
c_{h}+c_{t} & c_{t} h_{2} \\
c_{t} h_{2} & c_{r}+c_{t} h_{2}^{2}
\end{array}\right]\left[\begin{array}{c}
\dot{u}_{F} \\
\dot{\varphi}_{F}
\end{array}\right] \mathrm{d} t \\
E_{K_{\text {found }}} & =\int_{0}^{t}\left[\begin{array}{ll}
\dot{u}_{F} & \dot{\varphi}_{F}
\end{array}\right]\left[\begin{array}{cc}
k_{h}+k_{t} & k_{t} h_{1} \\
k_{t} h_{1} & k_{r}+k_{t} h_{1}^{2}
\end{array}\right]\left[\begin{array}{c}
u_{F} \\
\varphi_{F}
\end{array}\right] \mathrm{d} t \\
E_{D_{\text {super }}} & =\int_{0}^{t} \dot{\varphi}_{S} C_{\phi} \dot{\varphi}_{S} \mathrm{~d} t \\
E_{K_{\text {super }}} & =\int_{0}^{t} \dot{\varphi}_{S} K_{\phi} \varphi_{S} \mathrm{~d} t
\end{aligned}
$$

After the earthquake has finished, and the system has damped out completely, the kinetic energy and the recoverable strain energy vanish, being all the input energy dissipated by viscous damping and by yielding in the pier. 

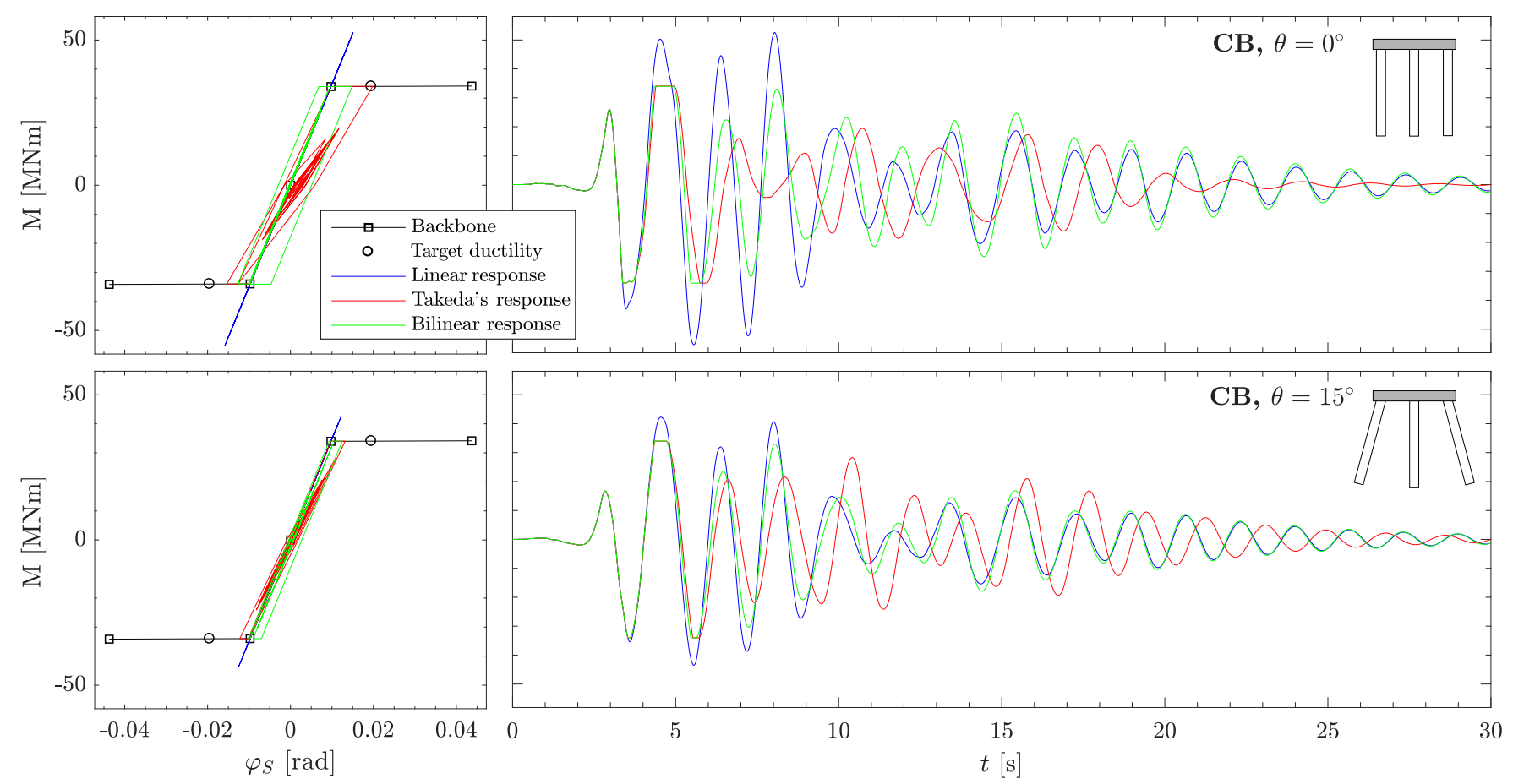

Figure 13: Hysteresis cycles and pier bending moment time histories for the H15L50 case (Table 4) with input motion E7 (Table 2). CB: compliant-base.

\section{Results}

\subsection{Inelastic responses}

In order to provide an idea of the structural responses computed through the presented methodology, Figure 13 shows the time history of the pier bending moment (right) and bending moment-chord rotation for the analysis case H15L50 (bridge with spans length of $50 \mathrm{~m}$ and piers height of $15 \mathrm{~m}$ ) subjected to input motion E7 (Table 2), considering vertical (upper plots) or $\theta=15^{\circ}$ inclined (lower plots) piles. Results computed using both Takeda's and bilinear approaches for modelling the nonlinear response of the pier hinge are shown together with the response obtained by assuming a linear model. The lengthening of the system period with pier degradation using Takeda's law becomes evident from the comparison of the responses by the three models.

The target ductility used in the design is also represented in Figure 13, for reference, with a circle. The ductility demand computed considering vertical piles and the Takeda's hysteretic rule coincides with the target ductility. On the contrary, in the configuration employing inclined piles, the magnitude of the response is significantly smaller, with a resulting ductility demand $(\mu=1.35)$ much smaller than the target ductility $(\mu=2.02)$.

At this point, it is important to remember that the non-linear response of the system is evaluated through a substructuring approach in which the frequency-dependent impedances of the foundations are incorporated using a simplified LPM. As discussed in Section 3.3, such simplified LPMs are not able to capture all the intricacies of both stiffness and damping functions (see Figure 7). For instance, resonance peaks due to the soil profile and to pile group effects are not correctly represented by the simplified model, and even static stiffnesses are not always perfectly estimated. In the case of the damping, the evolution of the function below the cut-off frequency is neither correctly captured. These variations could imply the variable of interest in this study (ductility demand) to be incorrectly computed, reason why validation of the proposed approach is needed. To this end, ductility demands for all superstructures and input motions have been computed through the equal 


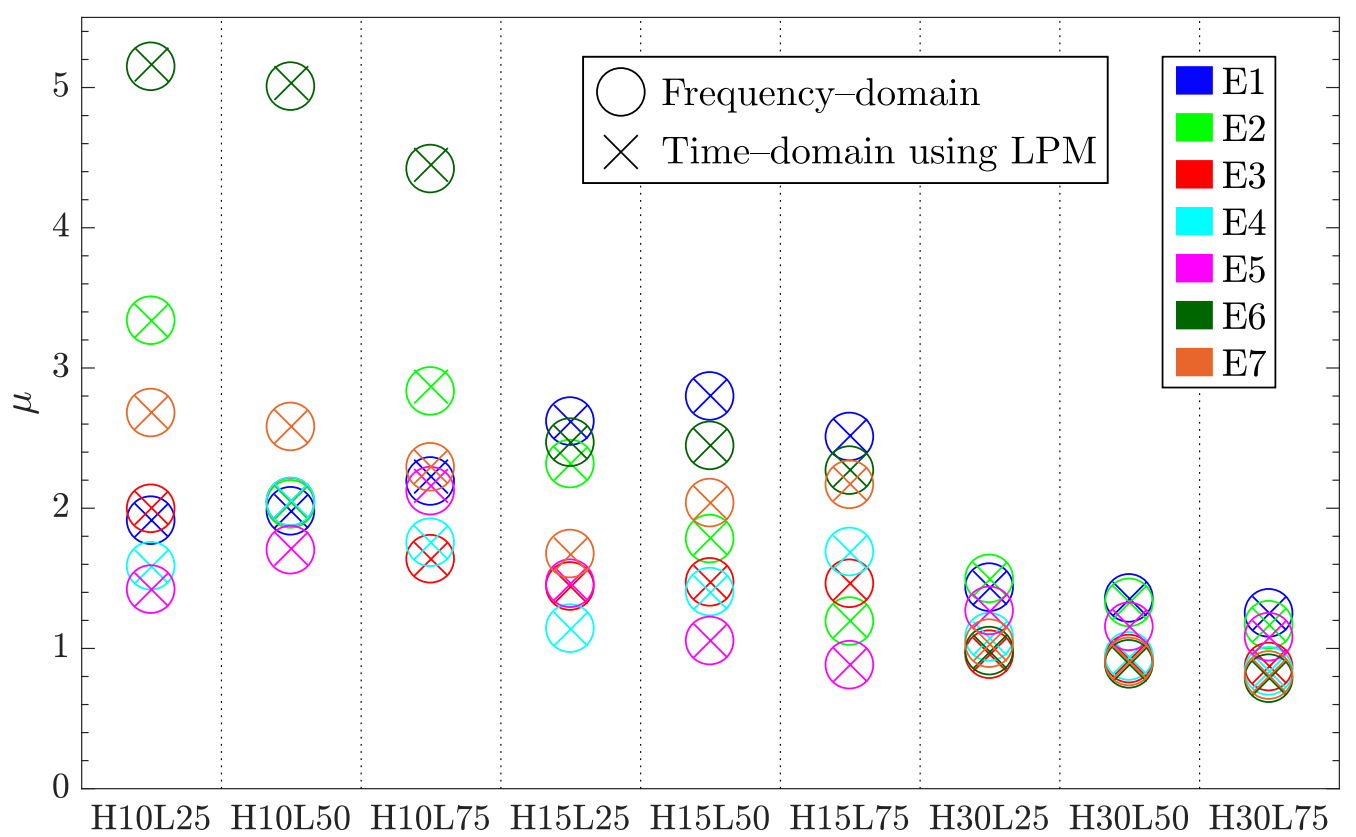

Figure 14: Comparison between the ductility demands, computed through the equal displacement rule, obtained in the frequency domain using the original impedance functions, and in the time domain using the LPM approximations. Vertical piles.

displacement rule [33] both in the frequency-domain, using the original impedance functions, and in the time-domain, using the derived LPM, finding that the differences between the two approaches are negligible. For the sake of brevity, Figure 14 only presents the results for the vertical pile foundations; each column corresponds to a different configuration and different colours are used for each earthquake. It can be observed that ductility demands computed from the two approaches coincide for each signal. As for the results scattering between the different seismic inputs, this is due to the different spectral ordinates of signals, in conjunction with the natural period of each superstructure (see Figure 2).

\subsection{Ductility demand}

The ductility demands computed for all cases included in the study are shown in Figure 15a. For each particular pier length-deck length configuration, results are presented for both $\mathrm{FB}$ and $\mathrm{CB}$ assumptions and, in the latter case, for the different piles rake angles, $\left(\theta=0^{\circ}, 5^{\circ}, 10^{\circ}\right.$ and $\left.15^{\circ}\right)$. Ductility demands obtained for each single input accelerogram are obtained using the equal displacement rule [33] (blue triangle), Takeda's (red x) or bilinear (green + ) hysteretic rules; while the mean value over the seven accelerograms is represented by a square. The scattering obtained between cases is due to the differences between elastic response spectra in the period range between the superstructure fundamental period $T_{n}$ and the effective period $T_{\text {eff }}$ (see Figure 2).

It is important to highlight that the ductility demands computed for many of the configurations are significantly smaller than the target ductility (even in FB cases and in configurations with vertical piles) because in most cases the reinforcement content has been overestimated due to standard requirements [22], either because of high stability indexes or because of the required minimum reinforcement ratio, corresponding to $1.0 \%$, as stated in Section 2.3. From an overall point of view, the increase in the number of rebars leads to higher yield strength and hence to a lower ductility demand. If standard requirements are not taken into consideration, and the guidelines of the displacementbased seismic design method are followed, results in terms of mean ductility demand match better with the target ductility (see Figure 15b). 

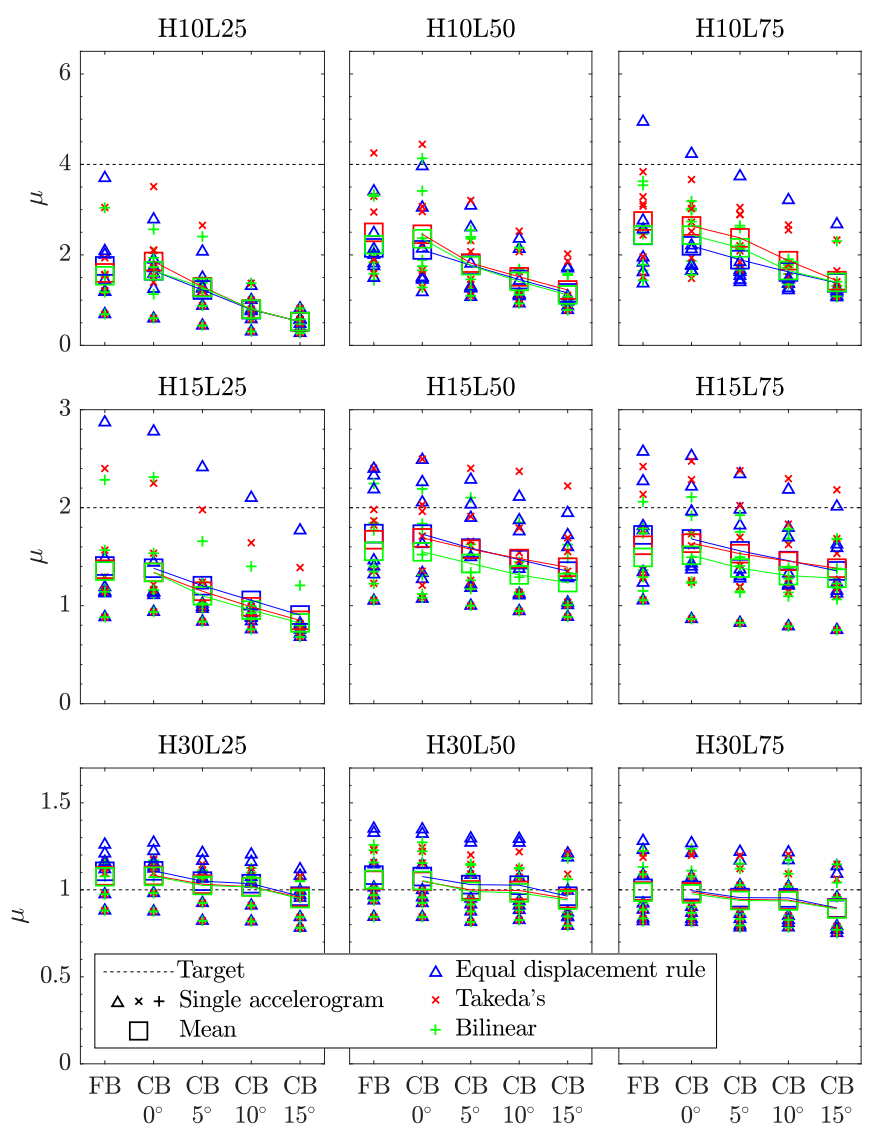

(a)
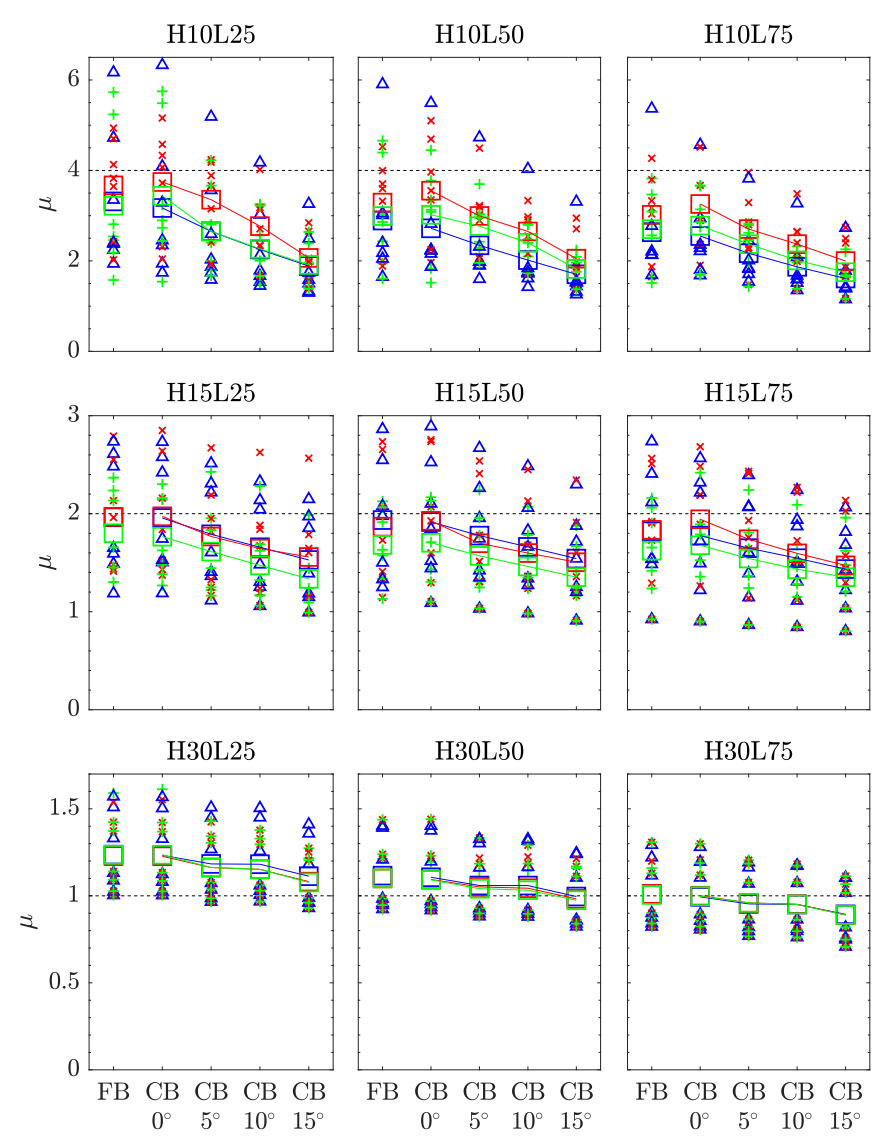

(b)

Figure 15: Ductility demand of all simulated cases. (a) Piers designed according to [18, 22], (b) piers designed according to [18] relaxing the restraints over minimum content of reinforcement and stability index [22]. FB: fixed-base, CB: compliant-base.

As expected, the use of Takeda's hysteretic rule leads, in general, to a better agreement with the target ductility demand when compared to the bilinear law assumption. In this sense, it is important to mention that the equivalent damping ratio $\xi_{e q}$ adopted for the piers design within the displacement-based procedure was calibrated for Takeda's type hysteretic model (Section 2.3). The general tendency in the underestimation of the ductility demand seen in Figure 15 when computed with a bilinear law is due to a higher amount of energy absorbed by the hysteresis cycle. Also, it is important to highlight the good estimations obtained following the equal displacement rule through linear analyses.

The higher the rake angle, the smaller is the ductility demand. A drastic reduction is observed for cases with the highest target ductility demand for rake angles of $\theta=15^{\circ}$ : for instance, the mean ductility demand decreases from $\mu=3.8$ to $\mu=2.0$ (-47\%) for the H10L25 case when piers are designed according to displacement-based procedure relaxing the standard restraints (Figure 15b), and from $\mu=1.9$ to $\mu=0.5(-74 \%)$ when the standard restraints are considered (Figure 15a). On the other hand, in higher piers with lower ductility demand, the reduction is much smaller, changing from a mean value of $\mu=1.1$ to a mean value of $\mu=1.0(-9 \%)$ in the H30L50 case, for example, when piers are designed according to displacement-based procedure relaxing the standard constraints (Figure $15 \mathrm{~b}$ ), and from $\mu=1.0$ to $\mu=0.9(-10 \%)$ when the restraints are considered (Figure 15a). The main cause of the reduction in the ductility demand is the conjunction of lower translational FIM and larger anti-phase induced translations due to rotations (see Figure 8) arising from the filtering action of the inclined pile foundations. 


\begin{tabular}{l|cccc|cccc|cccc} 
& \multicolumn{5}{|c|}{ H10L25 } & \multicolumn{4}{c|}{ H10L50 } & \multicolumn{4}{c}{ H10L75 } \\
$\theta$ & $0^{\circ}$ & $5^{\circ}$ & $10^{\circ}$ & $15^{\circ}$ & $0^{\circ}$ & $5^{\circ}$ & $10^{\circ}$ & $15^{\circ}$ & $0^{\circ}$ & $5^{\circ}$ & $10^{\circ}$ & $15^{\circ}$ \\
\hline$h_{S} \varphi_{S}$ & 88.9 & 90.6 & 91.7 & 92.2 & 83.3 & 85.8 & 87.3 & 88.0 & 77.8 & 80.8 & 82.7 & 83.5 \\
$u_{F}$ & 2.93 & 2.05 & 1.32 & 0.74 & 4.17 & 2.92 & 1.86 & 1.02 & 5.28 & 3.70 & 2.34 & 1.25 \\
$h_{F} \varphi_{F}$ & 8.22 & 7.33 & 6.98 & 7.04 & 12.5 & 11.3 & 10.9 & 11.0 & 16.9 & 15.5 & 15.0 & 15.2
\end{tabular}

\begin{tabular}{l|cccc|cccc|cccc} 
& \multicolumn{4}{|c|}{ H15L25 } & \multicolumn{4}{c|}{ H15L50 } & \multicolumn{4}{c}{ H15L75 } \\
$\theta$ & $0^{\circ}$ & $5^{\circ}$ & $10^{\circ}$ & $15^{\circ}$ & $0^{\circ}$ & $5^{\circ}$ & $10^{\circ}$ & $15^{\circ}$ & $0^{\circ}$ & $5^{\circ}$ & $10^{\circ}$ & $15^{\circ}$ \\
\hline$h_{S} \varphi_{S}$ & 96.3 & 96.9 & 97.2 & 97.4 & 94.16 & 95.05 & 95.6 & 95.7 & 92.1 & 93.2 & 93.9 & 94.1 \\
$u_{F}$ & 0.95 & 0.66 & 0.41 & 0.20 & 1.46 & 1.01 & 0.61 & 0.29 & 1.92 & 1.32 & 0.79 & 0.36 \\
$h_{F} \varphi_{F}$ & 2.71 & 2.42 & 2.35 & 2.44 & 4.38 & 3.94 & 3.83 & 3.99 & 6.03 & 5.46 & 5.33 & 5.57
\end{tabular}

\begin{tabular}{l|cccc|cccc|cccc} 
& \multicolumn{4}{|c|}{ H30L25 } & \multicolumn{4}{c|}{ H30L50 } & \multicolumn{4}{c}{ H30L75 } \\
$\theta$ & $0^{\circ}$ & $5^{\circ}$ & $10^{\circ}$ & $15^{\circ}$ & $0^{\circ}$ & $5^{\circ}$ & $10^{\circ}$ & $15^{\circ}$ & $0^{\circ}$ & $5^{\circ}$ & $10^{\circ}$ & $15^{\circ}$ \\
\hline$h_{S} \varphi_{S}$ & 99.1 & 99.3 & 99.3 & 99.3 & 98.7 & 98.9 & 99.0 & 98.9 & 98.2 & 98.5 & 98.6 & 98.5 \\
$u_{F}$ & 0.14 & 0.08 & 0.03 & 0.00 & 0.20 & 0.12 & 0.05 & -0.01 & 0.27 & 0.16 & 0.06 & -0.01 \\
$h_{F} \varphi_{F}$ & 0.73 & 0.66 & 0.67 & 0.72 & 1.09 & 0.99 & 1.00 & 1.09 & 1.49 & 1.35 & 1.37 & 1.49
\end{tabular}

Table 8: Degrees of freedom contribution (in percentage) to the total displacement at the deck $\left(h_{S}=h_{d}+h_{c}+h_{p}, h_{F}=h_{d}+h_{c}+h_{p}+h_{f}\right)$, according to Eurocode 8-Part 2 [22].

These results show that SSI effects can have a very significant influence on the piers ductility demand. However, standards usually recommend to include SSI effects in the analyses only when the soil-foundation flexibility contributes significantly to the total displacement at the top of the pier. For example, Eurocode 8-Part 2 [22] recommends in Section 4.1.4.(2) to include SSI if its contribution in terms of displacement obtained under the action of a unit horizontal load at the deck level is higher than $20 \%$. Table 8 presents the percentage contribution due to the pier deflection $\left(\left(h_{d}+h_{c}+h_{p}\right) \varphi_{S}\right)$, the foundation translation $\left(u_{F}\right)$ and the foundation rotation $\left(\left(h_{d}+h_{c}+h_{p}+h_{f}\right) \varphi_{F}\right)$ to the total displacement of the deck under a static force applied at the deck level. It is shown that the contribution of the soil-foundation flexibility is larger than $20 \%$ only in the H10L75 case, although the effect of SSI is quite significant in many of the rest of configurations. Furthermore, inclined piles reduce the contribution of the soil-foundation flexibility to the overall deck displacement, with respect to vertical piles, and their use tend to reduce significantly the ductility demand.

\subsection{Energy}

Figure 16 shows a typical result obtained from the analyses in terms of the energy time history for the H15L50 case with input motion E7, considering both vertical piles (upper plots) and inclined piles with $\theta=15^{\circ}$ (lower plots). The first column presents the energy terms computed assuming a linear-elastic system. The second and third columns, on the other hand, present the energy terms corresponding to the non-linear models in which the response of the pier plastic hinge is modelled adopting either Takeda's or the bilinear hysteretic rules, respectively. The input energy to the system $\left(E_{i n}\right)$ is represented by a black continuous line. As stated before, at each time step the input energy is balanced by the sum of the recoverable kinetic energy $\left(E_{I}\right.$, blue continuous line), the dissipated energy by damping $\left(E_{D}\right.$, orange continuous line), the recoverable strain energy and, in the non-linear cases, the dissipated energy by pier yielding ( $E_{K}$, magenta continuous line). The dissipated energy by damping and the recoverable strain energy are, at the same time, divided into the contributions of the superstructure or the soil-foundation system (dotted and dashed lines respectively). As time goes to infinity, the kinetic and the strain recoverable energies vanish, and all the input energy to the 

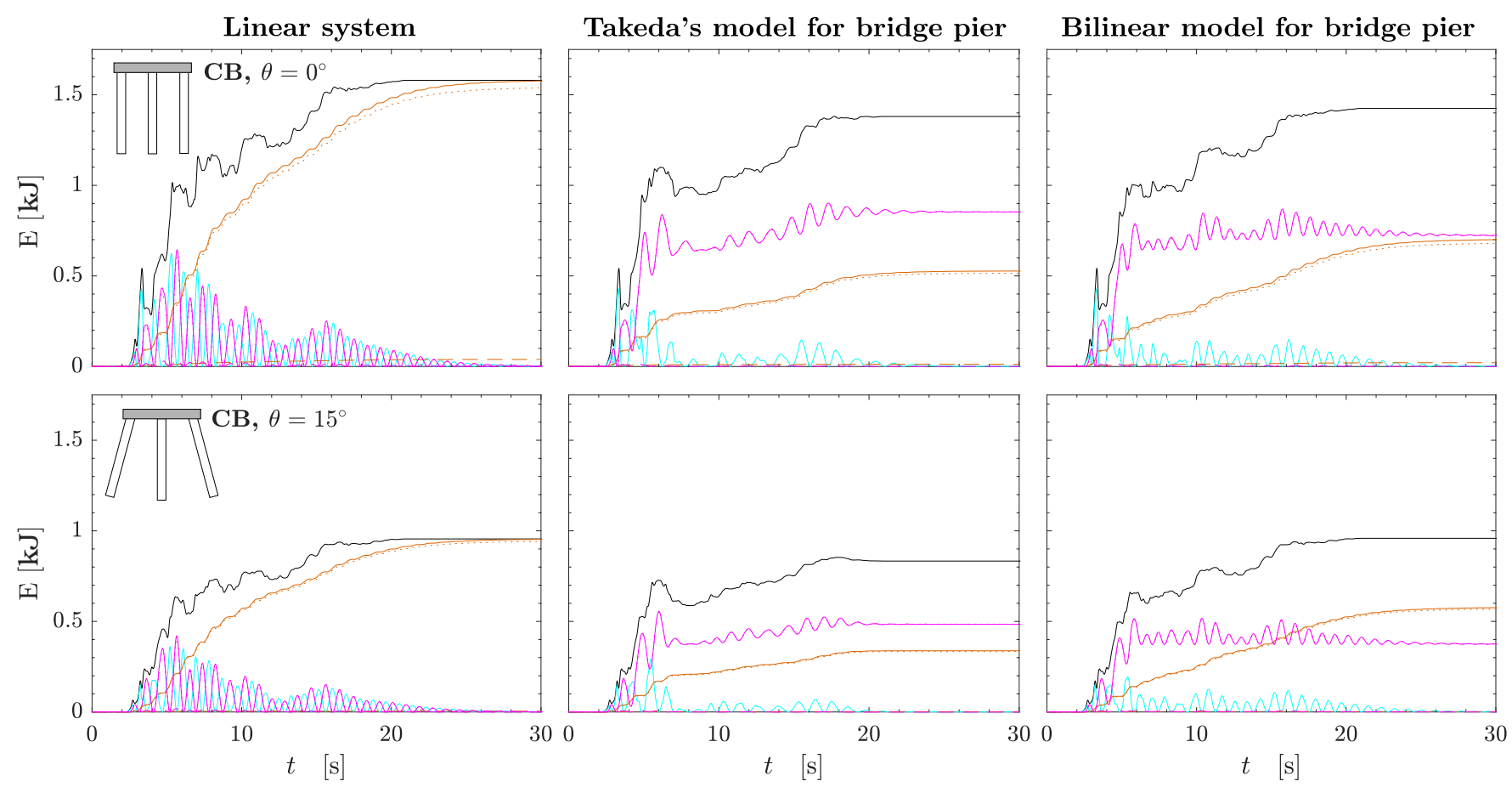

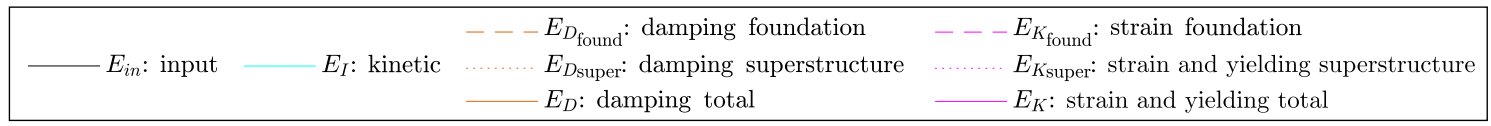

Figure 16: Time history of the energy terms for the H15L50 case with input motion E7. CB: compliant-base.

system has been dissipated by viscous damping in the superstructure and soil-foundation systems, and by yielding in the pier plastic hinge.

Important differences in the input energy, depending on whether inclined or vertical pile foundations are considered, can be observed. Furthermore, slight differences in the input energy can be observed depending on the model adopted (linear, Takeda's or bilinear). This is due to the fact that the input energy (Equation (5)) not only depends on the input accelerations, $\ddot{u}_{g}$ and $\ddot{\varphi}_{g}$, and the mass of the system $\mathbf{M}$, but also on the velocities time histories, $\dot{\varphi}_{S}, \dot{u}_{F}$ and $\dot{\varphi}_{F}$. When yielding occurs, part of the input energy is now dissipated by yielding instead of by viscous damping. At the same time, the higher effective periods imply smaller velocities in the system which, in turn, lead to smaller values of the energy components associated to viscous damping.

Figure 17 shows the mean over the seven accelerograms of the different energy terms at the end of the time history analyses in all structural cases relaxing the restraints over minimum content of reinforcement and stability index in the piers [22]. The different terms $\left(E_{D_{\text {super }}}\right.$ (black), $E_{D_{\text {found }}}$ (dark grey) and $E_{K_{\text {super }}}($ light grey)) are represented with stacked bar graphs that are grouped for FB or CB models, the latter presented separately for the vertical or inclined piles. Within each group, results are also separated for the Linear (L) models and for the non-linear models assuming Takeda's (T) or Bilinear (B) behaviours. The sum of the quantities in each vertical bar equals the mean input energy to the system $\left(E_{i n}\right)$ at the end of the time history analysis.

Generally, the energy dissipation through the foundation is relatively low (4.6\% of the input energy considering all CB systems). The input energy tends to increase with higher span lengths because of the associated higher masses. For increasing pier heights, the input energy is generally lower because of the lower velocities obtained in the system response. When the system behaves non-linearly, the input energy to the system decreases, in almost all configurations, with respect to the linear-elastic case and, the higher the target ductility demand (short pier cases), the smaller is 

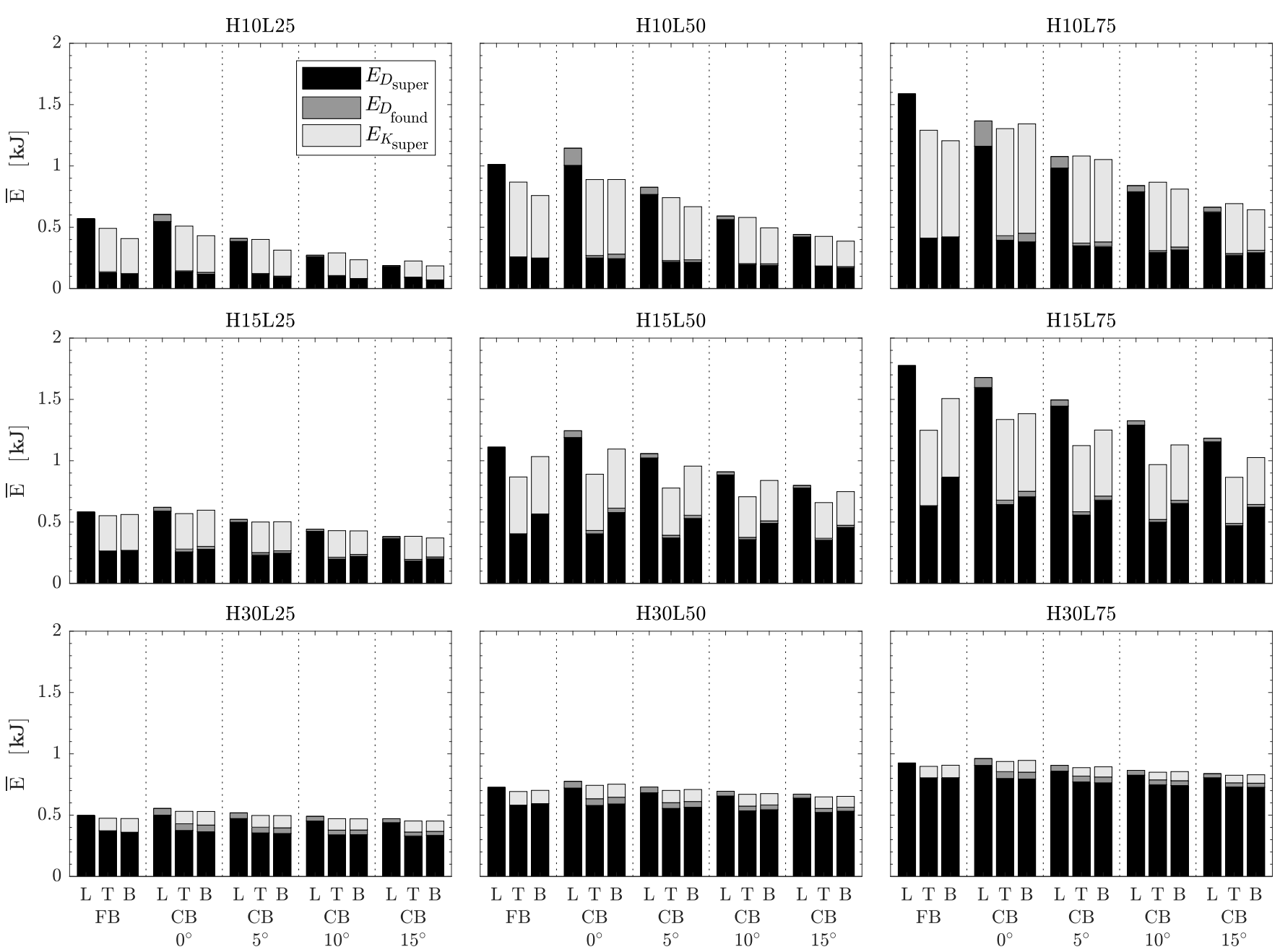

Figure 17: Mean over the 7 accelerograms of the energy balances at the end of the time history analyses for all structural cases. FB: fixed-base, CB: compliant-base, L: linear, T: Takeda's constitutive law, B: bilinear constitutive law.

the energy dissipated by viscous damping in the superstructure, effect that is counteracted by the energy dissipation by pier yielding.

As pile rake angle increases, the system receives less seismic energy. Again, this effect is more noticeable in the systems with highest ductility demand. The decrease in the input energy redounds more to the decrease of the dissipation energy by pier yielding than by viscous damping. The energy dissipated by pier yielding reduces drastically in some cases, as can be observed, for example, in H10L75 case. In this configuration, and considering for instance the model that assumes Takeda's hysteretic rule, the input energy to the system reduces by a significant $47 \%$ when inclined piles with $\theta=15^{\circ}$ are assumed instead of vertical piles, with reductions of the energies dissipated by yielding or by viscous damping of $53 \%$ and $31 \%$, respectively.

\section{Conclusions}

SSI effects on the seismic design and response of bridges founded on piles in soft soils have been investigated focusing on the role of pile inclination. Bridges with expected linear and non-linear behaviours have been designed according to a displacement-based approach, making use of bridgedeck-pier subsystems representative of the whole structural behaviour and assuming a fixed base hypothesis. Bridges with different piers heights and span lengths are included in the investigation. 
The SSI contribution to the seismic structural response has been studied in the spirit of the substructure approach through non-linear dynamic time history analyses considering a set of suitably selected real accelerograms.

Even in cases of complex soil profiles as the one considered in this study, the adopted low-order LPM is able to represent the frequency-dependent impedance functions of the different soil-foundation systems with enough accuracy when used to compute ductility demands and energy balances, even though such LPM is not able to reproduce all the intricacies of the impedance functions of the configurations considered in the analysis. In this regards, it has also being found that impedance functions and kinematic interaction factors computed through either a Winkler-type model or a coupled BEM-FEM model leads to virtually identical results.

Takeda's model is used to represent the non-linear response of the hinge developed at the pier's base. However, for the cases studied herein, it is shown that a good estimation of the ductility demand can also be obtained through a linear equivalent simulation adopting the equal displacement rule while a good estimation of ductility demand and energy dissipation by yielding can be obtained adopting a simple bilinear hysteresis law.

Strong variations in the inelastic response are obtained depending on the records used in the simulations, as previously observed, for instance, by Elnashai and McClure [11]. This leads to a strong scattering in the results in some cases. In this regard, a set of properly scaled records was proposed.

Disregarding SSI and referring to FB systems, if the seismic detailing prescribed by modern codes (e.g. Eurocode $8[23,22,40]$ ) is guaranteed, the actual structural response may differ sensibly from the expected one, driven by the design methodology, for all cases in which greater amounts of reinforcements are needed to comply with standards.

Concerning SSI effects, the following main conclusions can be drawn:

- despite only one particular case fall within conditions defined by Eurocode 8 for which SSI analyses are mandatory, the compliance of soil-foundation systems with inclined piles affect sensibly the bridge response in all cases.

- foundations with inclined piles promote a less pronounced non-linear behaviour of the superstructure and the ductility demand of piers reduces by increasing the pile inclination.

- the last can be explained by the peculiarities of the FIM of inclined pile foundations, characterised by rotations inducing anti-phase displacements in the superstructure with respect to the translational component of the motion, which are responsible for reductions in the seismic energy that enters the system and must be dissipated through viscous damping or yielding.

- the application of displacement-based design methodologies to bridges founded on inclined piles in soft soils requires the definition of a suitable strategy to account for the soil-foundation compliance in the design methodology.

Provided that a proper design is performed, accounting for the peculiar resisting mechanisms of inclined pile foundations, the latter appear beneficial for the bridge seismic response since, from an overall point of view, they are responsible for a reduction of the plastic rotation demand of piers hinges.

\section{Acknowledgements}

This study was supported by the Ministerio de Ciencia, Innovación y Universidades and the Agencia Estatal de Investigación of Spain, and FEDER, through research project BIA2017-88770-R. F. 
González is recipient of the FPU fellowship FPU14/06936 from the Ministerio de Ciencia, Innovación y Universidades of Spain, which also provided him with financial support (EST17/00370) for a short-term research stay at Università Politecnica delle Marche.

\section{References}

[1] M. B. Brito, H. Ishibashi, M. Akiyama, Shaking table tests of a reinforced concrete bridge pier with a lowcost sliding pendulum system, Earthquake Engineering \& Structural Dynamics 48 (3) (2019) 366-386.

[2] Y. Xie, J. Zhang, Design and Optimization of Seismic Isolation and Damping Devices for Highway Bridges Based on Probabilistic Repair Cost Ratio, Journal of Structural Engineering 144 (8) (2018) 04018125.

[3] Y. Li, J. P. Conte, Probabilistic performance-based optimum design of seismic isolation for a California high-speed rail prototype bridge, Earthquake Engineering \& Structural Dynamics 47 (2) (2018) 497-514.

[4] Y. Okui, K. Nakamura, T. Sato, T. Imai, Seismic response of isolated bridge with high damping rubber bearings, Steel Construction 12 (1) (2019) 2-9.

[5] C. Liu, R. Gao, B. Guo, Seismic design method analyses of an innovative steel damping bearing for railway bridges, Engineering Structures 167 (2018) 518-532.

[6] D. V. Bompa, A. Y. Elghazouli, Inelastic cyclic behaviour of RC members incorporating threaded reinforcement couplers, Engineering Structures 180 (2019) 468-483.

[7] Z. Wang, J.-Q. Wang, Y.-C. Tang, T.-X. Liu, Y.-F. Gao, J. Zhang, Seismic behavior of precast segmental UHPC bridge columns with replaceable external cover plates and internal dissipaters, Engineering Structures 177 (2018) 540-555.

[8] L. Zhao, K. Bi, H. Hao, X. Li, Numerical studies on the seismic responses of bridge structures with precast segmental columns, Engineering Structures 151 (2017) 568-583.

[9] A. A. Ghadban, N. I. Wehbe, T. Pauly, Seismic performance of self-consolidating concrete bridge columns, Engineering Structures 160 (2018) 461-472.

[10] M. Ciampoli, P. E. Pinto, Effects of soil-structure interaction on inelastic seismic response of bridge piers, Journal of Structural Engineering 121 (5) (1995) 806-814.

[11] A. S. Elnashai, D. C. McClure, Effect of modelling assumptions and input motion characteristics on seismic design parameters of RC bridge piers, Earthquake Engineering \& Structural Dynamics 25 (5) (1996) 435-463.

[12] G. Mylonakis, G. Gazetas, Seismic soil-structure interaction: beneficial or detrimental?, Journal of Earthquake Engineering 4 (3) (2000) 277-301.

[13] B. Jeremić, S. Kunnath, F. Xiong, Influence of soil-foundation-structure interaction on seismic response of the I-880 viaduct, Engineering Structures 26 (3) (2004) 391-402.

[14] G. Mylonakis, C. Syngros, G. Gazetas, T. Tazoh, The role of soil in the collapse of 18 piers of Hanshin Expressway in the Kobe earthquake, Earthquake Engineering \& Structural Dynamics 35 (5) (2006) 547-575. 
[15] N. Gerolymos, A. Giannakou, I. Anastasopoulos, G. Gazetas, Evidence of beneficial role of inclined piles: observations and summary of numerical analyses, Bulletin of Earthquake Engineering 6 (4) (2008) 705-722.

[16] C. Medina, L. A. Padrón, J. J. Aznárez, O. Maeso, Influence of pile inclination angle on the dynamic properties and seismic response of piled structures, Soil Dynamics and Earthquake Engineering 69 (2015) 196-206.

[17] S. Carbonari, M. Morici, F. Dezi, F. Gara, G. Leoni, Soil-structure interaction effects in single bridge piers founded on inclined pile groups, Soil Dynamics and Earthquake Engineering 92 (2017) 52-67.

[18] M. J. N. Priestley, G. M. Calvi, M. J. Kowalsky, Displacement-Based Seismic Design of Structures, IUSS Press, 2007.

[19] E. Kausel, R. V. Whitman, J. P. Morray, F. Elsabee, The spring method for embedded foundations, Nuclear Engineering and Design 48 (2) (1978) 377-392.

[20] T. Takeda, M. A. Sozen, N. N. Nielsen, Reinforced concrete response to simulated earthquakes, Journal of the Structural Division 96 (12) (1970) 2557-2573.

[21] M. C. Capatti, G. Tropeano, M. Morici, S. Carbonari, F. Dezi, G. Leoni, F. Silvestri, Implications of non-synchronous excitation induced by nonlinear site amplification and of soil-structure interaction on the seismic response of multi-span bridges founded on piles, Bulletin of Earthquake Engineering 15 (11) (2017) 4963-4995.

[22] EN1998-2, Eurocode 8 - Design of structures for earthquake resistance. Part 2: bridges, CEN, 2005.

[23] EN1998-1, Eurocode 8 - Design of structures for earthquake resistance. Part 1: general rules, seismic actions and rules for buildings, CEN, 2004.

[24] C. Smerzini, C. Galasso, I. Iervolino, R. Paolucci, Ground Motion Record Selection Based on Broadband Spectral Compatibility, Earthquake Spectra 30 (4) (2014) 1427-1448.

[25] N. Luco, P. Bazzurro, Effects of earthquake record scaling on nonlinear structural response, Report on PEER-LL Program Task 1G00 Addendum (Sub-Task 1 of 3), 2005.

[26] J. W. Baker, Measuring bias in structural response caused by ground motion scaling, In Proceedings of the 8th Pacific Conference on Earthquake Engineering. Paper Number 056.

[27] E. I. Katsanos, A. G. Sextos, G. D. Manolis, Selection of earthquake ground motion records: A state-of-the-art review from a structural engineering perspective, Soil Dynamics and Earthquake Engineering 30 (4) (2010) 157-169.

[28] F. Dezi, S. Carbonari, G. Leoni, A model for the 3D kinematic interaction analysis of pile groups in layered soils, Earthquake Engineering \& Structural Dynamics 38 (11) (2009) 1281-1305.

[29] L. A. Padrón, J. J. Aznárez, O. Maeso, BEM-FEM coupling model for the dynamic analysis of piles and pile groups, Engineering Analysis with Boundary Elements 31 (6) (2007) 473-484.

[30] J. P. Wolf, Soil-structure interaction analysis in time domain., Prentice-Hall, 1988. 
[31] F. González, L. A. Padrón, S. Carbonari, M. Morici, J. J. Aznárez, F. Dezi, G. Leoni, Seismic response of bridge piers on pile groups for different soil damping models and lumped parameter representations of the foundation, Earthquake Engineering \& Structural Dynamics 48 (3) (2019) $306-327$.

[32] S. Carbonari, M. Morici, F. Dezi, G. Leoni, A lumped parameter model for time-domain inertial soil-structure interaction analysis of structures on pile foundations, Earthquake Engineering \& Structural Dynamics 47 (11) (2018) 2147-2171.

[33] A. K. Chopra, Dynamics of structures. Theory and applications to earthquake engineering. Third edition., Prentice-Hall, 2007.

[34] L. A. Montejo, M. J. Kowalsky, CUMBIA - Set of codes for the analysis of reinforced concrete members, CFL Technical Rep. No. IS-07, 2007.

[35] J. B. Mander, M. J. N. Priestley, R. Park, Theoretical Stress-Strain Model for Confined Concrete, Journal of Structural Engineering 114 (8) (1988) 1804-1826.

[36] D. J. King, M. J. N. Priestley, R. Park, Computer Programs for Concrete Column Design. Research Report 86/12, Department of Civil Engineering, University of Canterbury, 1986.

[37] A. Aviram, K. R. Mackie, B. Stojadinović, Guidelines for Nonlinear Analysis of Bridge Structures in California. PEER Report 2008/03, Pacific Earthquake Engineering Research Center, University of California, Berkeley, 2008.

[38] M. J. N. Priestley, F. Seible, G. M. Calvi, Seismic Design and Retrofit of Bridges, John Wiley \& Sons, 1996.

[39] I. Takewaki, Closed-Form Sensitivity of Earthquake Input Energy to Soil-Structure Interaction System, Journal of Engineering Mechanics 133 (4) (2007) 389-399.

[40] EN1998-5, Eurocode 8 - Design of structures for earthquake resistance. Part 5: foundations, retaining structures and geotechnical aspects, CEN, 2004. 